\title{
The progress and trend of pro-environmental behavior research: a bibliometrics-based visualization analysis
}

\author{
Hui Lu ${ }^{1} \cdot$ Weibo Zhang ${ }^{1} \cdot$ Beidi Diao $^{1} \cdot$ Yan Liu $^{1} \cdot$ Hong Chen $^{1}$ (D) $\cdot$ Ruyin Long ${ }^{1} \cdot$ Shaohan Cai ${ }^{2}$
}

Accepted: 27 April 2021 / Published online: 30 June 2021

(C) The Author(s), under exclusive licence to Springer Science+Business Media, LLC, part of Springer Nature 2021

\begin{abstract}
Pro-environmental behavior (PEB) has always been a hot topic in academic and practical, and it is highly necessary to explore the research progress and development trend of PEB. Based on 1038 relevant literatures published and the Web of Science core database, this paper used citation analysis, co-word analysis and cluster analysis methods to systematically analyze the dynamic evolution process of PEB's research topics, knowledge base and subject areas. The results show that PEB research is currently in a period of rapid growth. And PEB research presents typical multidisciplinary characteristics, mainly focuses on PsychologyEducation-Social, Economics-Economic-Political, Environmental-Toxicology-Nutrition and other disciplines. Then, this study also finds that the PEB research hotspots mainly concentrated in seven directions such as "Environmental cognition, emotion and motivation process", etc., which can be further classified into three horizontal levels and three vertical levels. This study will provide valuable theoretical and practical reference for the future research of PEB.
\end{abstract}

Keywords Pro-environmental behavior $\cdot$ Bibliometric methods $\cdot$ Co-occurrence analysis $\cdot$ Cluster analysis $\cdot$ Basic knowledge

\section{Introduction}

As a critical force that could reduce the negative human impact on the ecological environment, pro-environmental behavior (PEB) has been a hot topic in the academic circles for the

Hong Chen

hongchenxz@cumt.edu.cn; hongchenxz@163.com

Hui $\mathrm{Lu}$

aloe525@126.com

Weibo Zhang

TS19070186A31@cumt.edu.cn

Beidi Diao

zgdzdxdlxdbd@163.com

Yan Liu

1019024617@qq.com

Ruyin Long

longruyin@163.com

Shaohan Cai

alan.cai@carleton.ca

1 School of Economics and Management, China University of Mining and Technology, Xuzhou 221116, China

2 Sprott School of Business, Carleton University, Ottawa, Canada past 10 years (Stern, 2011; Van der Werff et al., 2013; Hornsey \& Fielding, 2020; Lu et al., 2020). In particular, the current COVID-19 epidemic has severely harmed mental health, as well as global economic development. This forces people to rethink the relationship between humans and the ecological environment, and judge the impact of their own activities on the ecological environment (Kapecki, 2020). As such, one may expect PEB is not only a research hotspot in the past decade, but will also become an eternal topic in future.

The concept of PEB originated from the reflection by scholars on ecological problems in the 1960s (Ellen et al., 1991). For instance, Maloney and Ward (1973) maintain that 'the ecological crisis is a crisis of maladaptive behavior' (P. 583). They emphasized that human behaviors play an important role in the ecosystem and called on researchers to pay attention to human environmental behavior and changes of such behaviors. To date, scholars have labeled PEB by using different terms, such as Environmentally responsible behavior (Lee et al., 2013; Su \& Swanson, 2017; Cheung et al., 2019), Environmentally sustainable behavior (Kurz et al., 2007; Juvan \& Dolnicar, 2014; Geiger et al., 2019), Environmental significant behavior (Stern, 2011; Bratt et al., 2015; Moon et al., 2017), Green behavior (Gordon-Wilson \& Modi, 2015; Li et al., 2018; Kim et al., 2019), Ecological behavior (Testa et al., 2015; Otto \& Pensini, 2017; Liu et al., 2019b). Environmentally friendly behavior (Alp et al., 2008; 
Liobikiene et al., 2017; McCoy et al., 2018), etc. Despite the different labels, these terms commonly refer to the meanings expressed by these terms are rough similar, that is, human behaviors that are conducive to the healthy development of the ecological environment.

In recent years, many scholars have explored various issues related to PEB. First, researchers have identified various antecedents of PEB, including exogenous variables, such as institutional factors, economic factors, and social norms (Kerr et al., 2017; Otto et al., 2018), as well as endogenous variables, such as motivation, environmental knowledge, consciousness, values, attitudes, emotions, and responsibilities (Oskamp \& Schultz, 2005; Casalo et al., 2019). Second, researchers have examined PEB demonstrated by different parties, such as enterprises, residents, employees, consumers, tourists, farmers and others (Lu et al., 2019; Rezvani et al., 2018; Zhang et al., 2019; Wang et al., 2018). Third, researchers also explore the reasons for the differences of empirical research results between the same constructs from the perspective of the specific PEB field (Pickett et al., 1993; Kaiser, 1998; Tiefenbeck et al., 2013). Finally, researchers have examined PEB aiming to protect various resources, such as marine resources, energy, water, climate resources, land, and other resource types. While studying the aforementioned topics, researchers have adopted multidisciplinary research methods and theoretical models from fields such as Social psychology, Economics, and Education. For example, the Rasch model of psychology has been adopted to optimize the scales of general PEB attitudes or other subjective values. Bibliometrics method from Information Science \& Library Science has been utilized to provides the possibility for determining the external characteristics and inherent discipline of PEB; the research on psychedelic drugs in medicine also provided valuable findings related to $P E B$.

In summary, literature on PEB are multi-perspective and multi-orientation in nature. It is widely recognized that interdisciplinary research can provide multiple methods and technology for the solution of complex and comprehensive problems as well as the construction of related disciplines (Hennessey \& Amabile, 2010). Interdisciplinary research can also expand the application of theoretical knowledge in practice (Aboelela et al., 2007; Spano et al., 2020a). At the same time, interdisciplinary research is able to discover and create new research paradigms (Spano et al., 2020b). In particular, the characteristics of PEB literature publication, the emergence and evolution of PEB research fields and knowledge base, research hotspots and discipline characteristics of PEB research in recent years can dynamically present the past and present of PEB related research, and can even predict the future trend of PEB research. However, to the best of our knowledge, there is a lack of literature review that systematically describes the research themes, knowledge base, and dynamic evolution of PEB studies. Therefore, our research aims to explore the evolutionary law of PEB research from the aspects of subject characteristics and topic characteristics on the basis of combing the existing PEB literature, and further to support new research fields and research topics that may arise in the future. To achieve this goal, we first obtained relevant articles from the web of science (SCI and SSCI) database is used as a data pool in our study. We then utilized Citespace, Bibexcel and Pajek software packages to present the dynamic evolution process and law of PEB research in detail. Specifically, in order to systematically present the subject characteristics and topic characteristics of PEB, our research is intended to explore the six important research issues, namely, Publication status of PEB literature, Research fields and knowledge base of PEB research at different time phases, Research hotspots of PEB research, Mainly research directions of PEB, Cross-disciplinary of PEB research topics at different time phases, and multidisciplinary composition. For answering the above questions, our research tried to explore it from the following four research blocks namely Status of Literature Publication, Evolution of Research Fields, Cooccurrence Analysis of Keywords, and Cluster analysis of high-frequency keywords.

\section{Research Method and Data}

\section{Research Method}

We first used the two functions of Citespace software, such as time zone map of the subject field and the Dual-Map Overlay of the journal, to explore the subject field, knowledge base and evolution law related to the studies of PEB. This software package, however, also come with several weakness. It is difficult for the software to analyze the relationship among literatures (Chen et al., 2019). Moreover, the clustering labels generated by Citespace software are not representative, so that co-word clustering is not suitable for locating research hotspots (Xie et al., 2020). Therefore, we additionally utilized software packages such as Excel, Bibexcel and Pajek to construct a co-occurrence network of high-frequency keywords, and further explored hot topics at different periods. Finally, we used Pajek software to perform a cluster analysis on highfrequency keywords, and explored the research topics covered by PEB literature and the potential future trend of PEB research.

Citation analysis is a bibliometric research method that presents the citation phenomena of journals, papers, authors and other analysis subjects, and reveals the inherent laws contained therein (De Bellis, 2009). Researchers often regard the frequently cited articles as more important than others (Garfield, 1979). The frequently cited articles also reflects the mainstream of the research field and constitute the knowledge base or knowledge structure for future research (Hou 
et al., 2018). One of the most widely used citation analysis software is the Citespace bibliometric visualization package developed by Dr. Chen (Chen, 2004; Chen, 2006; Chen \& Leydesdorff, 2014). Particularly, the package enables researchers to conduct, Dual-map overlay analysis, which is a new way to determine the subject area, knowledge base or knowledge structure related to a specific research topic (Chen \& Leydesdorff, 2014; Hou et al., 2018). This analysis has the potential to reveal changes in citation knowledge patterns at the subject level (Chen \& Leydesdorff, 2014). Therefore, for the current study, we first utilized Citespace software to automatically extract the "SC" field from data text after data cleaning, and drew a time zone map of the subject area. Next, we drew the dual-map overlay of the journals to explore the subject knowledge base and evolution process of PEB literature.

Co-Word analysis is a content analysis method for cooccurrence analysis of representative phrases which is developed by Callon in 1983 (Callon et al., 1983). The method allows researchers to find the relationship among complex events (Callon et al., 1983). In practices, Co-Word Analysis is often used to count the frequency of a pair of phrases (terms, keywords, etc.) appearing in the same subject, and constructs their co-occurrence matrix to reflect the relationships among these phrases (Ronda-Pupo \& Guerras-Martin, 2012). For the current study, we conducted Co-Word Analysis by using Bibexcel software, which can extract and count the frequency of phrase occurrences, and generate co-occurrence matrix (Ronda-Pupo \& Guerras-Martin, 2012; Hou et al., 2015; Zhang et al., 2017b). Specifically, in the current study, we focus on analysis of keywords of relevant articles. Keywords are refined vocabulary selected by the author that can represent the content or theme of the article. We maintain that the keywords are appropriate frequency phrases for co-occurrence analysis, which can show the core of the related researches (Ding et al., 2001). Therefore, we processed keywords of relevant articles and used them as representative phrases (The processing of keywords will be explained in section 2.2). Cooccurrence analysis of these keywords enables us to obtain the overall picture of a research field including the research theme, the internal structure of the research theme, and the theme evolution process. In this study, high-frequency keywords were first extraced by using Bibexcel software. Next, a high-frequency keyword co-occurrence matrix was built. Then we used a large-scale network visualization tool, Pajek software, to draw a high-frequency keyword co-occurrence network map to further explore the structure and evolution of the research topic.

Cluster analysis is essentially based on specific algorithms to classify the similarity of multiple indicators of data. The method is widely used in natural and social science studies for the purpose such as confirming the bio-ecological characteristics (e.g., Jiang et al., 2004), the attributes of the disease (e.g., Moore et al.,
2010), and research topics in a certain field (e.g., Li et al., 2015). The keyword co-occurrence matrix shows the co-occurrence frequency between keywords, and the higher co-occurrence frequency suggests that the research topics are closely related to each other (Zong et al., 2013). Therefore, the major groups of the research topics can be identified based on the cluster analysis of the high-frequency keyword co-occurrence matrix (Chen et al., 2016; Liu et al., 2018; Chen et al., 2019). In recent years, the more commonly used cluster analysis visualization software includes Citespace, Pajek, Gephi, Ucinet, Netdraw, etc. (Zhao \& Chen, 2014). Recall that in the first stage of our research, we utilized Citespace software package. However, due to lack of representative clustering tags, co-word clustering method available in this package is not suitable for finding research hotspots (Xie et al., 2020). Furthermore, it is difficult to utilize Citespace to analyze the relationship between various documents (Chen et al., 2019). To resolve this problem, we utilize best way is to use a combination of Excel, Bibexcel and Pajek software together to perform high-frequency keyword co-occurrence analysis and high-frequency keywords Cluster analysis. In addition, we also use Pajek to extract and display a single clustering network function (Batagelj \& Mrvar, 1998), which allows us to identify the internal laws of each cluster.

\section{Data Collection and Processing}

For the current research, we search for studies on PEBs in the Web of Science core data system. The retrieval process is as follows: First, we identify one set of keywords for PEBs by reviewing relevant literatures. Next, we include synonymous phrases to the keywords, in order to expand the search scope and obtain comprehensive document data. The literature search formula was set as, TS = ("pro*environment* behavio*"OR"environment* friendly behavio*"OR"green behavio*"OR"ecological behavio*"OR"environment* responsible behavio*"OR"environment* significant behavio*"OR"environment* sustainable behavio*"OR"volunteer environment* behavio*"OR"organi*ational environmental citizenship behavio*"OR"organi*ational citizenship behavior for environment"OR"OCBE"). The search document type was set to "Article", the document language was set to English, the search scope was set to "SCI" and "SSCI", and the search time range was from 1900 to 2020 (the date ends on June 30, 2020). The search yielded a total of 1361 relevant papers. However, some of these articles are irrelevant to PEB but related to topics such as Online Consumer Brand Engagement, Organic Carbon Burial Efficiency, Non-human Ecological Behavior, etc. After deleting those in relevant articles, we obtained 1038 papers were obtained for this research.

We preprocessed the original keywords of 1038 documents before conducting the keyword co-occurrence analysis. Specifically, we first entered the keywords of each paper into 
Excel line by line. During the process, we found that keywords are missing for several papers. After discussing with three experts on co-occurrence analysis, we decided to identify keywords for these papers based on their content. Next, we processed the keywords by using the following procedures: first, we screened the keywords to combine those differ only in terms of capitalization, full name and abbreviation, and singular and plural, as well as those are synonyms. For example, "Emotion" was combined with "Emotions". "theory of planned behaviour", "planned behavior", "TPB" and "Ajzen's theory of planned behaviour" were all labeled as "Theory of planned behavior". "motivation", "Intrinsic motivation", "Environmental motivation" and "Autonomous motivation" were all labeled as "Motivation". Next, keywords that are irrelevant to the purpose of the current research, for example, specific country names, specific research methods, were all deleted. Finally, we kept one of the repeated keywords in the same paper. Overall, this process resulted in 1666 keywords for further analysis.

\section{Analysis and Results}

\section{Status of Literature Publication}

In order to predict the trend of the number of future publication in this field, we first conducted a descriptive analysis of the amounts of articles published in international journals related to PEB. The curve depicting the number of papers published on PEB is shown in Fig. 1. (As of June 30, 2020). It was in 1979 that the first paper on PEB was published. Between 1979 and 2020, the annual and cumulative number of published papers on PEB had been generally rising. In order to further analyze the emotionally pattern of PEB research, we divided the period into three phases based on the annual quantity index (1) the budding phase (1979-1990), when the publication on this topic is rare, (2) the exploratory phase (19912013), publication on the topic is between 2 and 50, and (3) the rapid-growth phase (2014-2020), when annual publication is more than 50. Specifically, the budding phase lasted
12 years; In the 23 years of the exploratory phase, the quantity of the published papers had shown relatively slow growth, and the accumulative publication quantity 361 of the papers accounted for $34.78 \%$ of the total number; In the rapidgrowth phase, the number of the publication showed a sharp increase every year. Within merely 7 years, the cumulative number of the published papers inquiries dramatically to 675 , i.e. around $65.03 \%$ of the total.

These articles are published in more than 300 journals. Among them, the top 20 journals with the largest number of publications were presented in Table 1 . The top 3 journals in terms of the number of publications are Environment and Behavior, Journal of Environmental Psychology, and Sustainability. The scope of these journals are highly compatible with the theme of PEB.

\section{Evolution of Research Fields}

The theory and practice of PEB are typical interdisciplinary characteristics in nature (Stern, 2011; Forstman \& Sagioglou, 2017; Meijers et al., 2019). For current study, the time zone map of subject categories in Citespace software is utilized to analyze the subject characteristic of PEB. Based on the classification of Web of Science research fields, we draw the evolution map of the PEB research field (see Fig. 2), in order to analyze the evolution process of this research fields. To balance the comprehensiveness and accuracy of the results, the parameters were set as follows: time range 1979-2020, time slice was 2 years, TOP100, Threshold Interpolation (C, $\mathrm{CC}, \mathrm{CCV})$ was set to $(0,0,0),(3,3,30),(3,3,30)$.

In the Fig. 2, the year only represented the time when the research field first appeared, and the size of the circle represents the number of documents in the research field. Along the time axis, research on PEBs first appeared in the following disciplines: Environmental sciences \& Ecology, Environmental studies, Education \& Educational research. Then Psychology was applied to PEB research, more disciplines were involved in the next decade, including Business, Business \& Economics, Economics, Political science, Government \& Law, Sociology, Green \& Sustainable science
Fig. 1 Literature number of proenvironmental behavior (as of the end of June 2020)

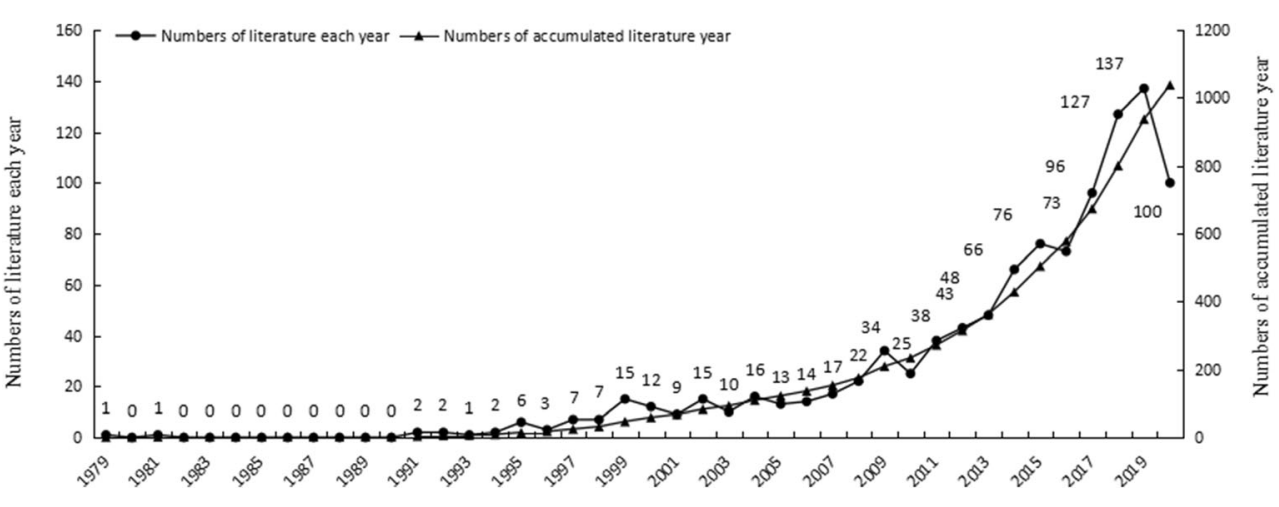


Table 1 Top 20 journals for the number of publications on pro-environmental behavior

\begin{tabular}{llll}
\hline Journal & N & Journal & N \\
\hline Environment and Behavior & 91 & Tourism Management & 13 \\
Journal of Environmental Psychology & 88 & International Journal of Hospitality Management & 13 \\
Sustainability & 64 & Business Strategy and The Environment & 13 \\
Journal of Cleaner Production & 51 & Society \& Natural Resources & 12 \\
Journal of Sustainable Tourism & 28 & Corporate Social Responsibility and Environmental Management & 12 \\
Environmental Education Research & 24 & Social Behavior and Personality & 11 \\
Frontiers in Psychology & 20 & Resources Conservation and Recycling & 10 \\
International Journal of Consumer Studies & 16 & Energy Policy & 9 \\
Journal of Business Ethics & 15 & Journal of Environmental Education & 9 \\
Journal of Applied Social Psychology & 15 & Journal of Business Research & \\
\hline
\end{tabular}

\& Technology, etc. As shown in Fig. 2, in the past 5 years (2016-2020), PEB researchers additionally addressed the issue from new perspectives such as Energy \& Fuels, Geography, Engineering, Development studies, Ethics, etc. Meanwhile, as for the perspective of the number of documents in the subject area, the Environmental sciences \& Ecology field is the one with most publications on PEB, with 544 documents. Followed by 397 papers from Environmental studies, 343 papers from Psychology, 239 papers from Psychology Multidisciplinary, and 228 papers from Environmental sciences.

Furthermore, our study used the A Dual-Map Overlay map of Citespace software to deeply analyze the subject knowledge base and evolution process of PEB. A Dual-Map Overlay is composed of two parts. The left part is the world of citing documents, and the right part is the world of documents cited in the left part. The citing area and the cited area are divided into 12 and 40 clusters respectively, and the discipline clusters are labeled by terms selected from the titles of journals in the corresponding clusters (Leydesdorff et al., 2013). The citation curve of the map points from left to right to its cited documents, aiming to clarify the citation track from "source" to "destination". At the same time, by analyzing the network structure of the co-citation map of the journal on the right, the knowledge base and evolution process of the research topic can be obtained. Next, Clicked "JCR Journal Maps" in "Overlay Maps", then clicked "Add Overlay", we used the Z-Score algorithm to standardize the citation links, in order to present the citation relationship between the journals on the left and the right more concisely. The analysis result in two obvious citation tracks (shown in Fig. 3), and the main information of Fig. 3 was listed in Table 2. Figure 3 and Table 2 jointly show journals that published citing documents related to the theme of $\mathrm{PEB}$ were mainly concentrated in

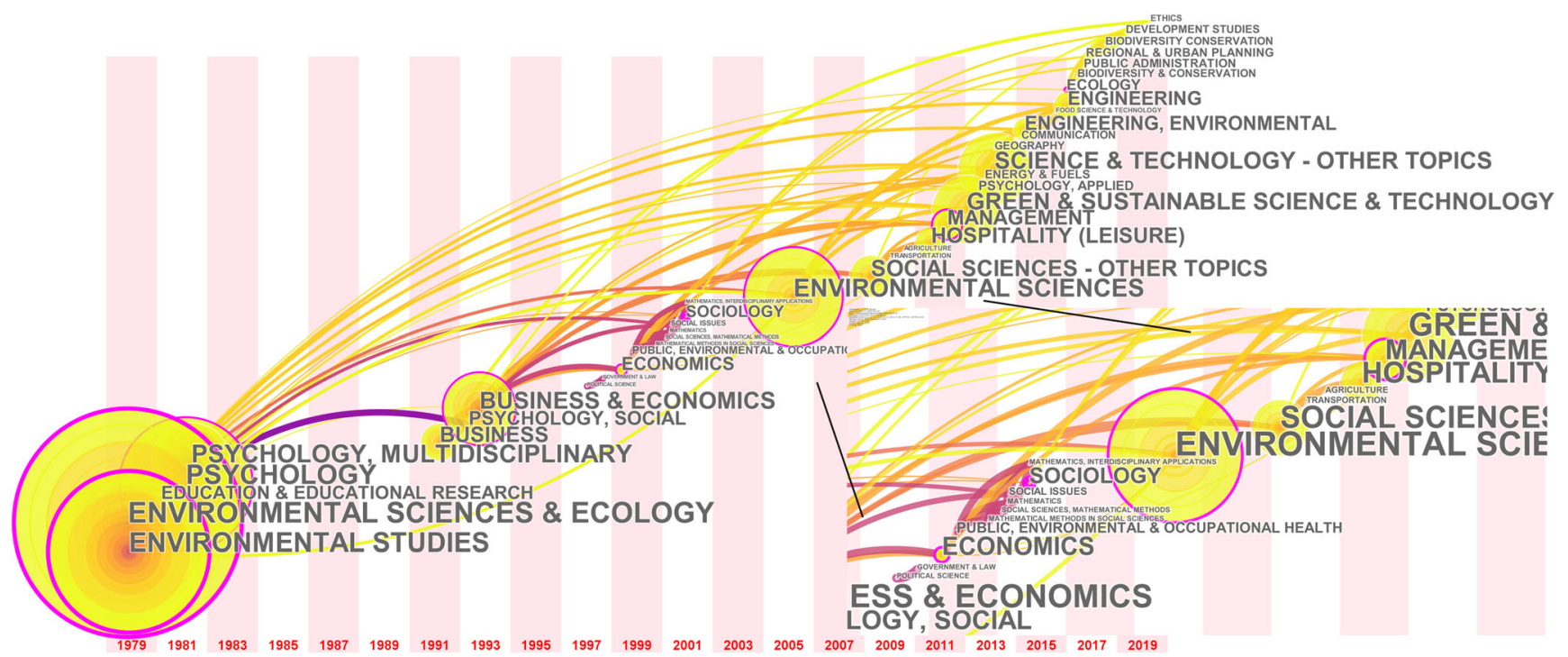

Fig. 2 The evolution of the research field of pro-environmental behavior from 1979 to 2020 
cluster A: psychology-education-health. Correspondingly, the reference curve mainly points to the economic-political and psychological-education-society. This result revealed that economics-politics and psychology-education-society were the most important and fundamental theoretical part of the basic knowledge system of PEB research.

Next, we used the changes of co-citation patterns in A Dual-Map Overlay map to reflect the evolution process of basic knowledge of PEB (see Fig. 4). The text data were processed based on the above-divided time stages. Then, we use "Show Cocitation Links" function of the software to obtain the co-citation map of the journal in Fig. 4. The co-cited networks of the three selected time periods were represented by yellow, red, and blue dotted lines. As strong a Fig. 4, the research on $\mathrm{PEB}$ was related to the following disciplines: Psychology-Education-Society, Economics-EconomicPolitics, Plant-Ecology-Zoology, EnvironmentalToxicology-Nutrition, Earth-Geology-Geophysics, Molecular-Biology-Genetics, Systems-ComputingComputer. Among them, articles in the fields of Psychology-Education-Society and Economics-EconomicPolitics have received the most citations. The collective citation behavior shows a different pattern among the three periods. There was no co-cited data from 1979 to 1990 . In contrast, from 1991 to 2013, citations were mostly related to disciplines such as Psychology-Education-Social, EconomicsEconomic-Political, Plant-Ecology-Zoology and Environmental-Toxicology-Nutrition. However, the citation pattern changed from 2013 to 2019. Researchers began to cite more relevant disciplines, including Earth-GeologyGeophysics, Molecular-Biology-Genetics, and SystemsComputing-Computer. The details of the findings will be discussed in 4.1 .

\section{Co-Occurrence Analysis of Keywords}

In order to reveal the main topics and evolutionary processes related to the theme of $\mathrm{PEB}$, we chose to analyze the key words of the corrected articles. As mentioned above in section 2.2, 1666 keywords were retained after processing. This study identified 107 high-frequency keywords which are used by more than 5 articles for further analysis. First, the Bibexcel software was used to generate a co-occurrence matrix of 107 rows * 107 columns, Next, the network analysis tool Pajek software was used to convert the excel file into a .net file, and finally form a co-occurrence network diagram of high- frequency keywords (shown in Fig. 5). Figure 6 is a cooccurrence network diagram based on keywords with a frequency larger than 10 .

In the Fig. 5 and Fig. 6, the blue color block represents the co-occurrence frequency of the keywords. The larger the color block, the higher the co-citation frequency in the literature. The network line represents the relationship of the keyword co-occurrence frequency in the same paper. The more lines (thicker) originated from a certain key word, the closer the connection between this key word (Yang et al., 2012), and the more important of this keyword. To highlight the patterns among the key words, the keywords with larger color blocks were placed in the middle of the figure manually. As shown in Fig. 6, the keywords such as Attitudes, Values, Proenvironmental behavior intentions, Sustainable consumption, Education, Tourism, Sustainability, knowledge, Environmental concern are most prominent among the articles studying PEB. They are related to the theory of planned behavior (TPB), value - belief - norm theory (VBN), norm activation theory (NAT) and self - determination theory.

To be specific, several groups of high-frequency co-occurrence keywords can be obtained by observing the highfrequency keyword co-occurrence matrix. For instance, most PEB articles surrounding the keyword "Value" also focus on keywords such as Attitudes, PEB intentions, Beliefs, Environmental concern, Personal norms, etc. Another example, most PEB articles researching "PEB intentions" also study Attitude, Values, tourism, etc. While articles concentrating on the keyword Sustainable consumption more often also discuss Attitudes, Sustainability, PEB intentions, consumer behavior, etc. In Fig. 5, although the keywords at the edge of the map were not the key content of PEB research, some of them may become hotspot words in the future research, such as Political orientation and sustainable design.

\section{Cluster Analysis of High-Frequency Keywords}

We conducted cluster analysis by using the "VOS clustering" function in Pajek software. Based on the high-frequency keyword co-occurrence matrix, 7 clusters were obtained, (see Fig. 7). The purpose of the analysis is to analyze the level attribution of various cluster from different levels such as individual-organization-society. Specifically, the context of "theoretical basis-theoretical development-theoretical application" was used to deeply analyze the knowledge evolution process presented by various clusters.
Table 2 Main information of Fig. 3

\begin{tabular}{lll}
\hline Curve number & Citing domain & Cited domain \\
\hline A1 & Psychology/Education/Health & Psychology/Education/Society \\
A2 & & Economics/Economic/Politics \\
\hline
\end{tabular}




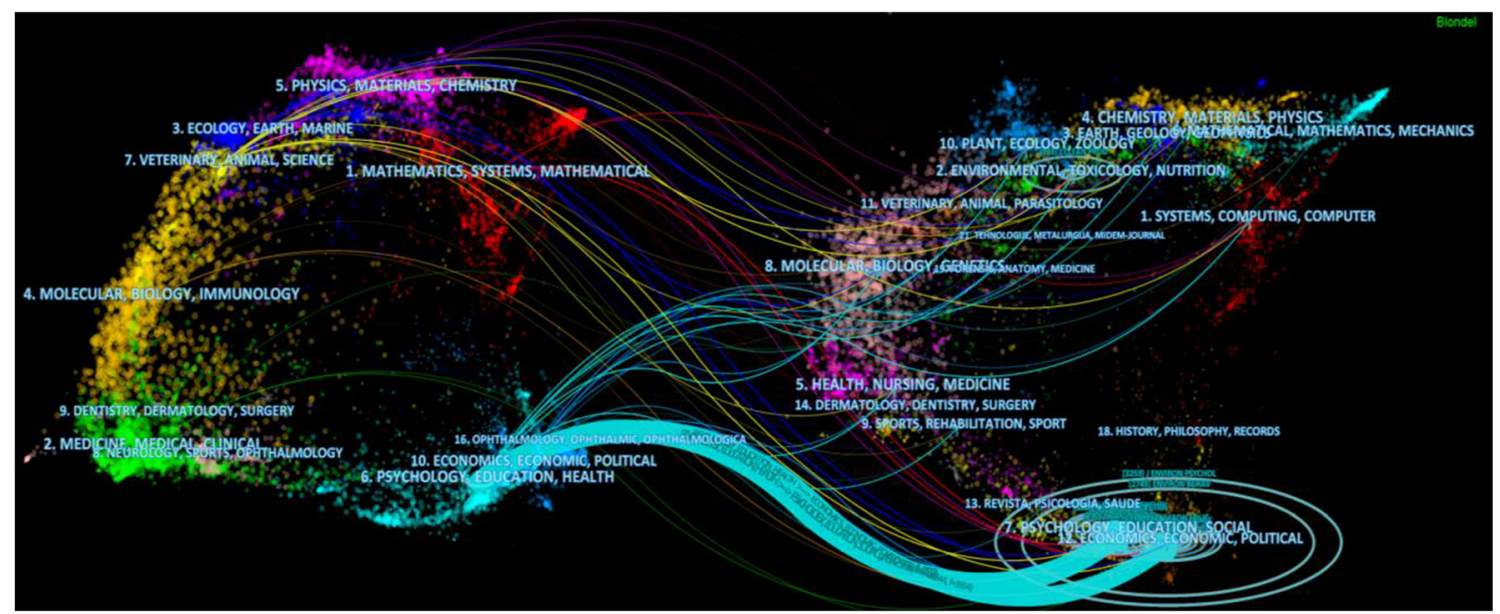

Fig. 3 Dual-map overlay of pro-environmental behavior literature

The cluster analysis results showed that the high-frequency keywords of PEB could be classified into seven categories (see Fig. 7). Based on the meaning of every high-frequency keywords, we labeled the identified seven clusters as: Environmental cognition, emotion and motivation process $(\mathrm{C} 1)$, Environmental values, attitudes and knowledge $(\mathrm{C} 2)$, Pro-environmental intentions, ethical characteristics and practices(C3), Organization sustainable development strategy and social responsibility implementation(C4), Sustainable tourism management(C5), Energy conservation behaviors' intervention and changes(C6) and Environmental policies, norms and Sustainable consumption(C7).

Specifically, C1 was related to the basic psychological process factors such as cognition, emotion and motivation that affect individual PEBs, C2 mainly focused on how individuals' internal psychological characteristics (such as values and attitudes) and external variables (such as socio-economic factors, demographic variables) affect their environmental behavior decisions, $\mathrm{C} 3$ explored the relationship between the ethical variables (e.g., individual's environmental responsibility, personal norms, religious beliefs) and various specific PEBs. C4 was related to the interaction mechanism between organizational constructs and the PEB of employees. C5 involved the researches on the sustainable development of ecotourism and hotel accommodation. C6 was on how interventions such as green rewards and punishments and product ecological attribute design can increase individual energy saving behavior, interventions and changes. $\mathrm{C} 7$ was mainly concerned with the formulation of environmental governance policies, the relationship between different types of norms such as subjective norms, descriptive norms, and imperative norms and specific PEBs, and the promotion strategies of sustainable consumption behaviors.

Likewise, these clusters show that the study of PEB has experienced three evolutionary processes: theoretical foundation, theoretical development and theoretical application.

Fig. 4 The collective citation model during three periods

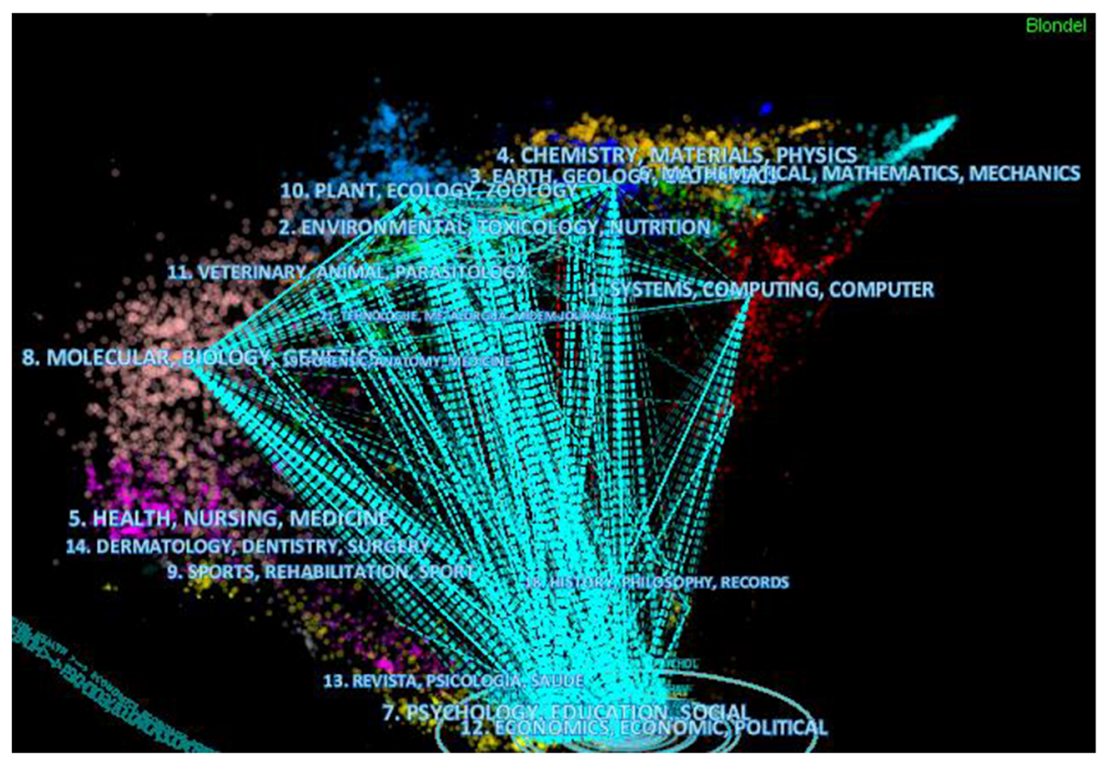




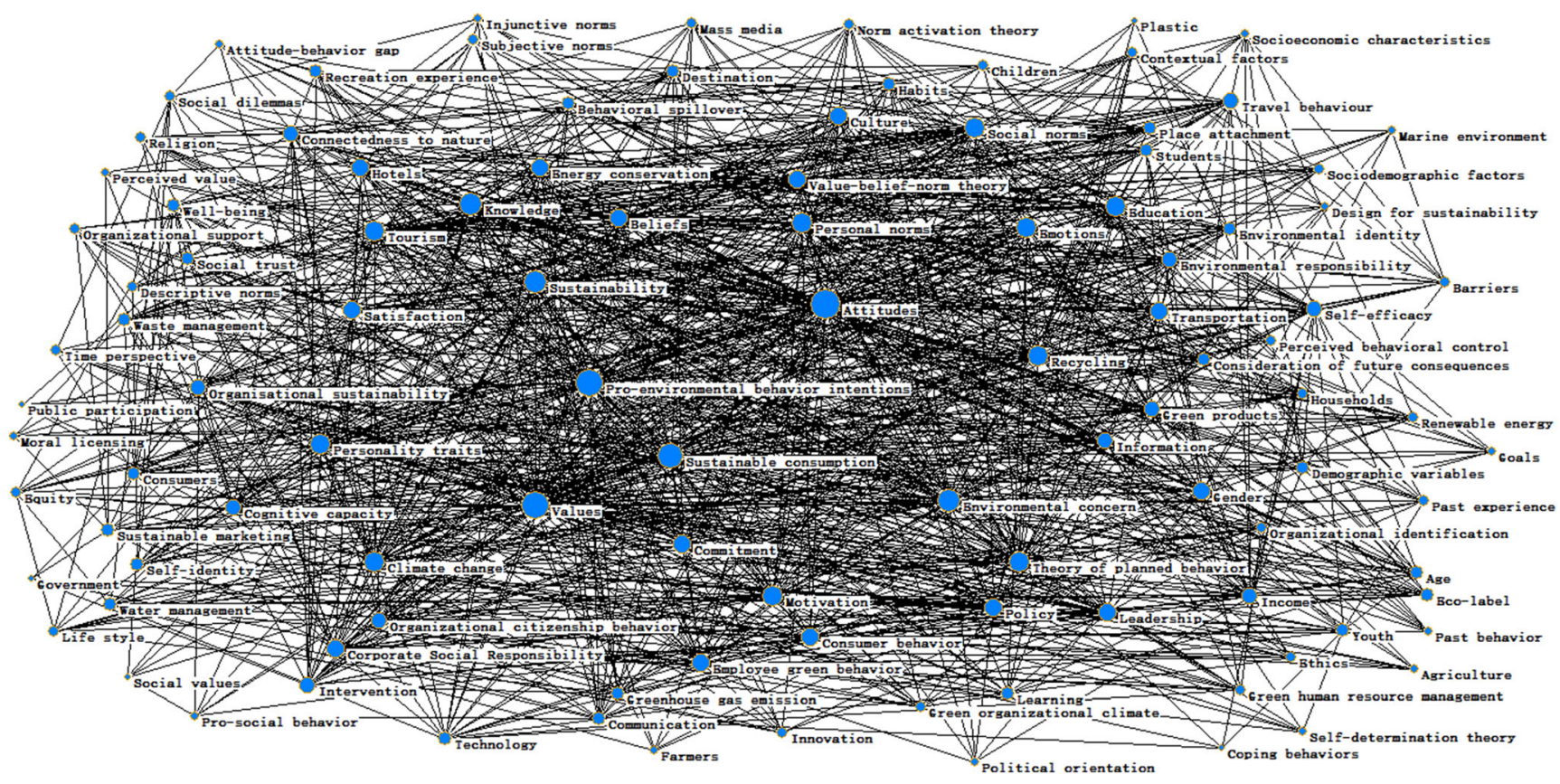

Fig. 5 Co-occurrence network of 107 high-frequency keywords

Specifically, C1 and C2 involve psychology-educationsociety knowledge, focusing more on individual-level attitudes, values, cognition and other psychological characteristics and intervention measures. Therefore, these studies laid theoretical foundations for the follow-up multidisciplinary application of PEB. C3, C4 and C5 are related to the theoretical developments of PEB. At this stage, by integrating theories from Business, Management, Hospitality (Leisure) and other disciplines, scholars have expanded the scope of PEB research from focusing on the individual psychological factors to the investigation on the intervention and change of specific PEBs, organization environmental management, and the realization of responsibilities, and sustainable tourism management. Finally, $\mathrm{C} 6$ and $\mathrm{C} 7$ are related to theoretical applications of PEB. At this stage, the research on PEB shows a more diverse knowledge structure. Some researchers drew on the theories from Green \& Sustainable science \& Technology, Science \& Technology-other topics, etc. and focuses on the development of green products at the social level and the promotion of sustainable consumption; whereas some others

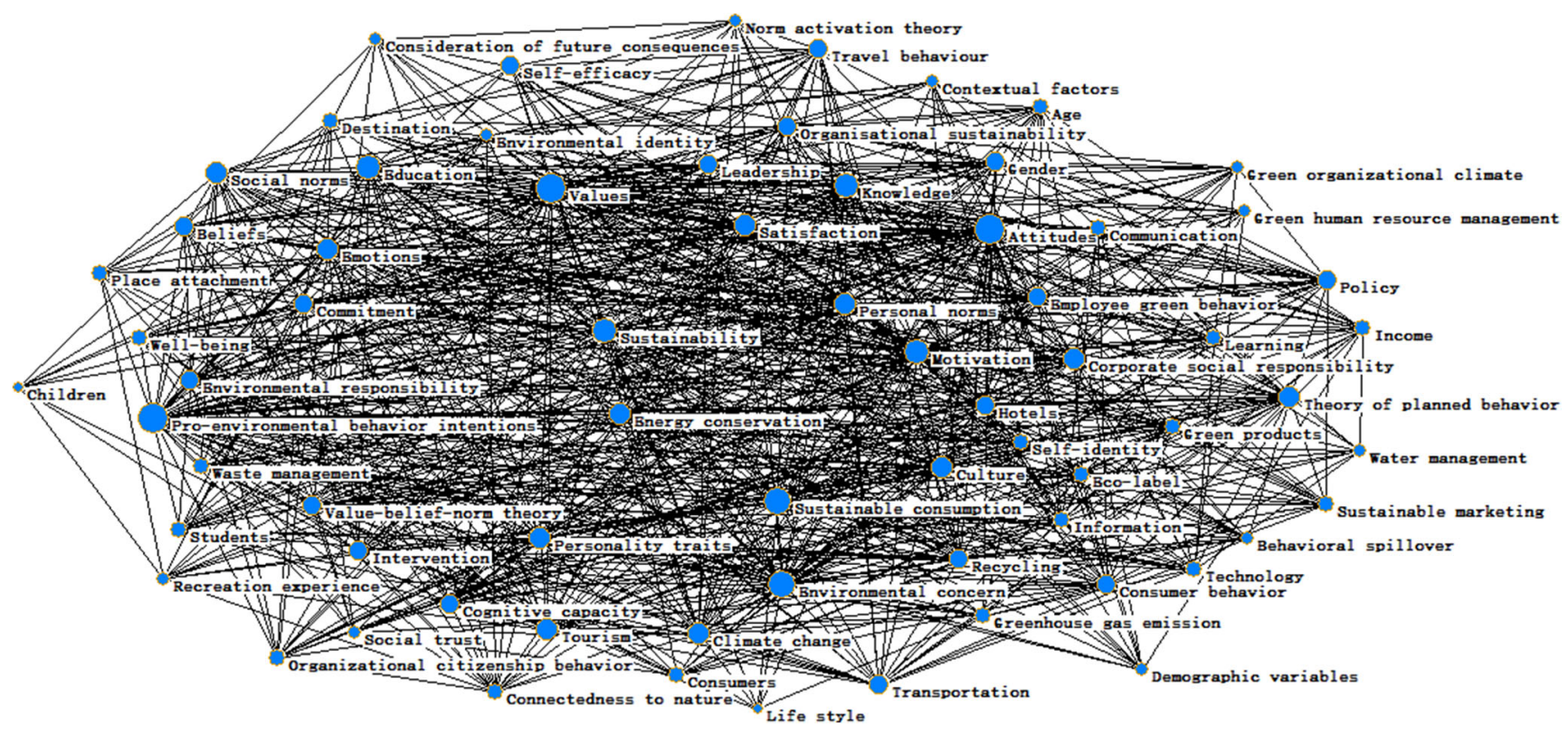

Fig. 669 co-occurrence network of high-frequency keywords 
$\mathrm{C} 1$ :Environmental cognition,emotion and motivation process

$\mathrm{C} 2$ :Environmental values, attitudes and environmental knowledge

C3:Pro-environmental intentions, ethical characteristics and practices

$\mathrm{C} 4$ :Organization sustainable development strategy and social responsibility implementation

C5:Sustainable tourism management

C6:Energy conservation behaviors' interventions and changes

C7:Environmental policies,norms and Sustainable consumption
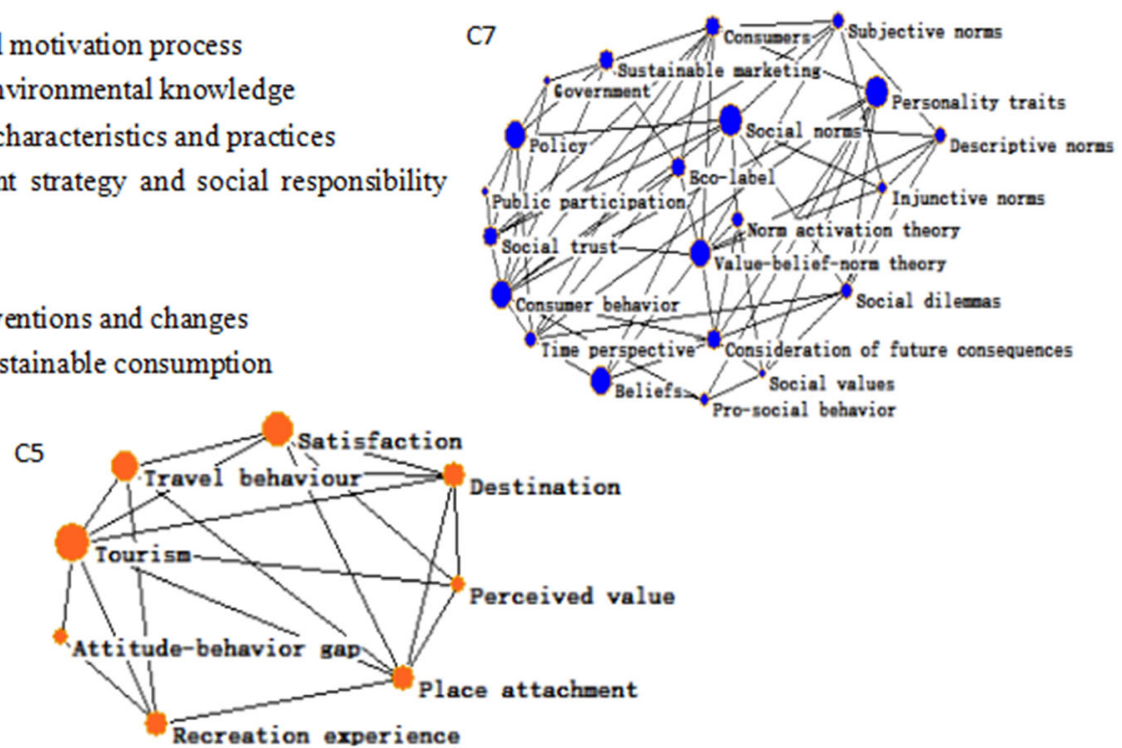

Social level

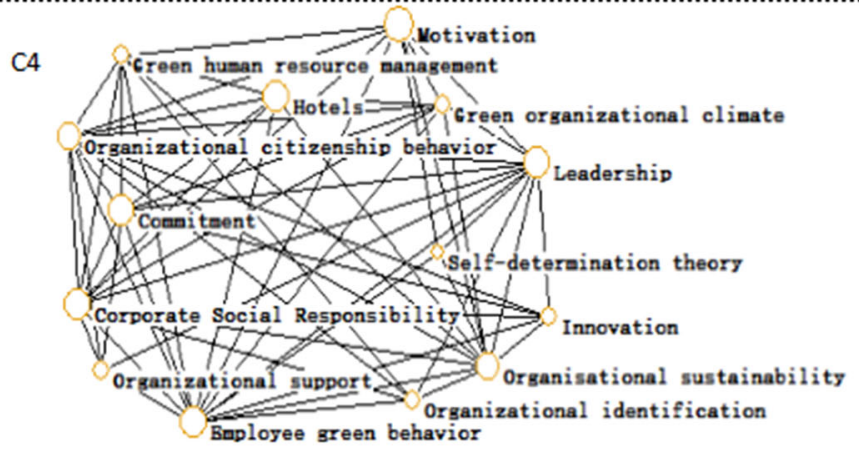

Organizational level

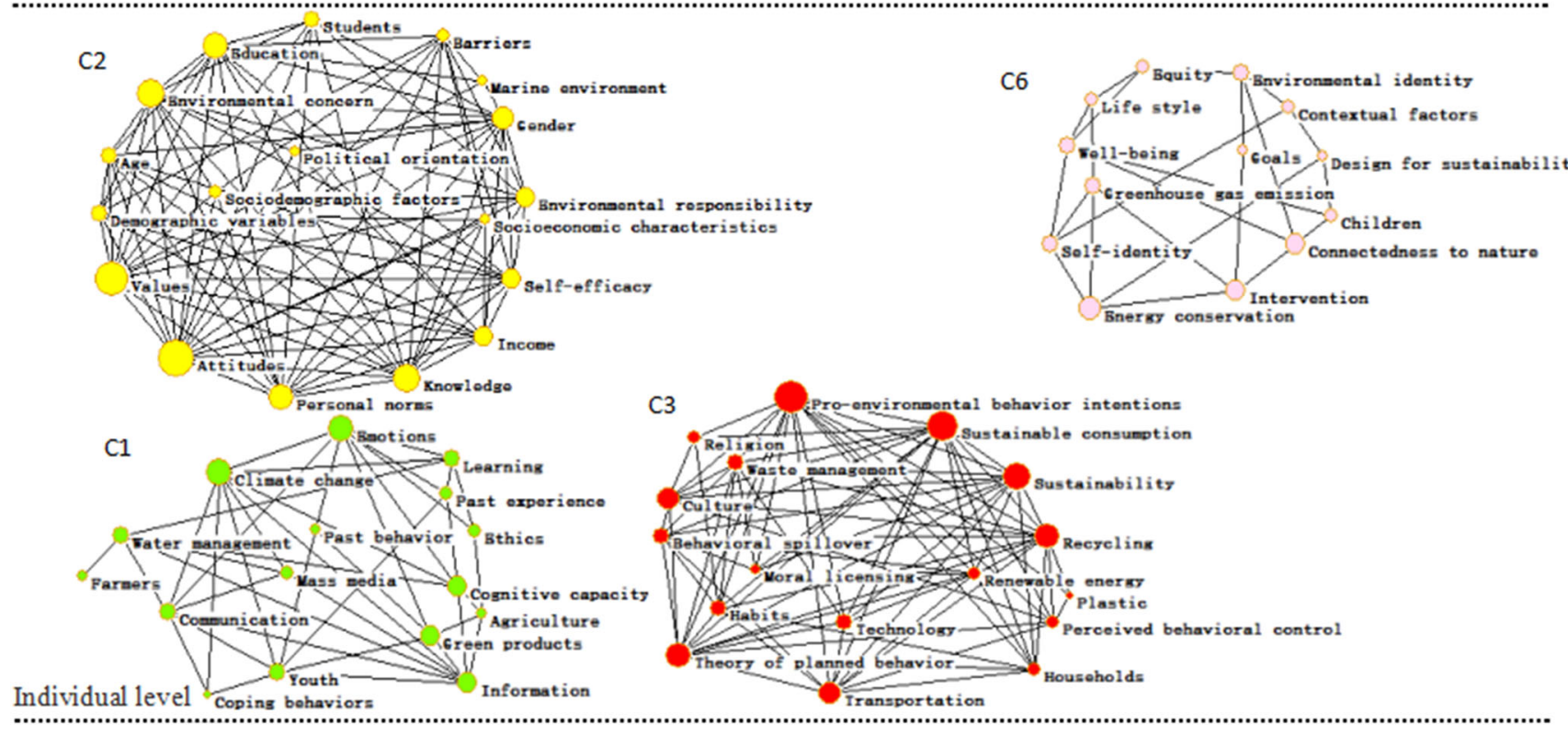

Theoretical foundation

Theoretical development

Theoretical application

Fig. 7 Cluster analysis of high-frequency keywords of pro-environmental behavior

drew on theories from Energy \& Fuels, Engineering, Environmental and other disciplines, focusing on the intervention and change of individual energy saving behavior.
Furthermore, from the perspective of individualorganization-society integration, PEB research at the individual level mainly focuses on individual values, attitudes, 
education, differences in environmental cognition, and intervention and changes in specific PEBs. The PEB research at the organizational level mainly focuses on leadership, organizational citizenship behavior, and the realization of corporate social responsibility. The researchers on social aspect is mainly concerned with sustainable tourism, the formulation of environmental policies, environmental regulations and the promotion of sustainable consumption.

\section{Discussion}

\section{Developing Trend under the Perspective of Time}

\section{The Budding Phase}

As shown in Fig. 2, there were only two articles published during the budding period with a 9-year stagnation. Specifically, as mentioned previously, Maloney and Ward called on scholars to pay more attention to human environmental behavior in environment issues in 1973. To answer the call, researchers drew on theories and findings from psychology and environmental science field to develop environmental psychology. In 1979, the trend led to a claim from environmental psychologist Borden that environmental psychology was in its formative period.

Environmental psychology aims to explore the psychological characteristics and behavioral patterns of people in terms of environmental activities, and to achieve environmental protection and harmony between man and nature through various intervention. During the budding period, psychologists began to explore the formation mechanism of PEB from the perspective of environmental psychology, which was given great expectations for solving environmental problems. For example, Borden and Schettino (1979) investigated the internal psychological relationship among the three components of environmental attitudes: emotion, cognition, and behavior. They found that (1) environmental emotion explained $7.9 \%$ of the variance variation of actual commitments, which was higher than the personal knowledge level ( $\omega 2=0.041)$; (2) Environmental emotion explained $12 \%$ of the variance variation of oral promises; and (3) while environmental ecological knowledge only accounted for 0.4\%. In another article, Buunk (1981) studied the relationship between utility (measured by the importance of environmental degradation in the participants' minds), environmental ecological knowledge, sense of effectiveness, and PEB. The results show that environmental ecological knowledge have the highest correlation with PEB, followed by sense of effectiveness and utility.

\section{The Exploratory Phase}

From the end of the twentieth century to the beginning of the twenty-first century, the increasingly severe environmental problems caused by the third industrial pollution has motivated many scholars to study PEB. On the one hand, the exploratory research on environmental issues from the perspective of environmental psychology has been continuously deepened and refined in the vertical direction; on the other hand, the horizontal, interdisciplinary integration also gradually emerged in this period. Therefore, we label this period "Exploratory period".

Specifically, in this period, an increasing number of studies have explored the impact of individual psychological variables (such as values, attitudes, beliefs, self-efficacy, etc.) on the formation mechanism of individual PEBs. Some studies adopted classical theories, such as Theory of Reasoned Action, VBN, NAT, TPB, etc., to explain and construct conceptual models of PEB. For example, Chan used TPB to predict the intention and actual behavior of individuals voluntarily using recycling containers (Chan, 1998). The results of the experiment conducted by Harland et al. (1999) showed that, compared with the TPB, the PEB intention and self-reported environmental protection measures explained by VBN have a greater variance proportion. However, Kaiser et al. (2005) showed that, compared to the VBN model, TPB could explain protective behaviors better.

Moreover, the distinction between general PEB and specific PEB also attracted attention from scholars. General PEB refers to behaviors based on universal environmental values or attitudes, while specific PEB refers to certain specific environmental behaviors such as sustainable consumption behavior and recycling behavior (Kaiser, 1998). Some studies have shown that the implementation of a specific PEB will negatively offset other specific PEB (e.g., Tiefenbeck et al., 2013); whereas others reported that different environmental behaviors are only slightly correlated (e.g., Pickett et al., 1993). Moreover, researchers recognize that one should not focuses on only individuals' behaviors but ignores the interaction between the persons and the context that they are embedded in (such as family, workplace, and tourist sites). Such negligence could result in the systematic bias of research findings. Rather, it is important to study the interaction between individuals and social context, and how such interactions affect environment issues. For example, consumer behaviors could be influenced by the corporate green marketing strategy (Fitchett \& Prothero, 1999; Cornelissen et al., 2007), the corporate environmental strategic decision-making influenced by stakeholders (Rojsek, 2001; Fairchild, 2008; Fraj-Andres et al., 2009), the individuals' PEB at workplace (Daily et al., 2009; Boiral \& Paille, 2012; Paille et al., 2013), the sustainable management of travel destination taking in account the tourist demands (Dolnicar \& Leisch, 2008), etc. Those factors have become the focus of the current PEB research.

As for cross-sectional research during "exploratory period", researchers have noticed that the study of PEB needs to incorporate more knowledge from various disciplines. Psychologist Vlek (2000) argued that solving environmental 
issues shall involve a comprehensive integration of multiple theories and methods. Moreover, plenty of knowledge from other disciplinaries is available for such effort. Especially, knowledges from disciplines such as physics, biology and economics are crucial for determining other potential elements of environmental issues (Vlek, 2000). Since then, an increasing number of studies have been conducted on the integration between disciplinary knowledge of Business, Economics, and Hospitality and PEBs. For instance, Dolnicar et al. (2008) have studied environment-friendly tourists. They reviewed literatures concerning environment-friendly tourist information in top and sustainable tourism journals. Their findings suggest that the tourism-destination managers need to appeal to the parties with sustainable travel demand by promoting the sustainable development of tourism destination. However, there is only a limited number of articles taking this approach. As pointed out by Young and Middlemiss (2012) the application of multi-disciplines and various viewpoints is in urgent need, and the demand for multi-disciplines shall be the development trend in the future.

\section{The Rapid-Growth Phase}

We identified 675 articles in the rapid growth phase (20142020). During this period, the research of PEB shows a significant cross-integration pattern, such that the theories from medicine, biology, economics and other disciplines are all further integrated into the research of PEB. For instance, Forstman and Sagioglou (2017) found that whoever has the psychedelic (e.g., Lysergids, Psilocybin) experience can internally better identify with the natural world, and consequently improve his/her personal PEBs. Zhang et al. (2017a) used spatial econometrics models to test the spatial dependence of carbon dioxide emissions at the provincial level in China. They discovered that carbon dioxide emissions had a strong spatial spillover effect, and suggested that all provinces should strengthen collaboration to mitigate climate change. Toni et al. (2018) found that the TPB model is also applicable to the collaborative economy, which is a modern consumption model based on the concepts of "using is more valuable than possessing the commodity itself" and "collaboration and sharing" (Rifkin, 2015). They suggested that TPB can achieve the target of sustainable social development by guiding consumers' attitude, behavioral intention and behaviors towards sharing and cleansing. In sum, the aforementioned studies suggest that interdisciplinary knowledge provides diversified development directions for the study of PEB, and could play a direct or indirect role in promoting the ultimate target of ecological sustainability. As the researchers increasingly paid attention to individual attitudes, values and awareness of PEB during this phase, they carried on a number of employees' green behavior, leadership, organizational citizenship behavior for the environment, corporate sustainability and other related aspects in the organization. This line of research concerns with the PEB of individuals in work situations and the influence of leadership at the organizational level (Kim et al., 2017). Moreover, macro-concepts such as climate change response, recycling, policies and social norms have also attracted much attention. As such, interdisciplinary research on PEB was being conducted in full swing in this phase. Nevertheless, the number of such articles has not reach the peak. Thus, the increasing PEB research within the past decade shall enjoy a sustained growth from this study.

\section{Analysis of the Three Levels}

\section{Individual Level of PEB}

\section{C1 Environmental Cognition, Emotion and Motivation Process}

The articles in this cluster are based on knowledge from psychology-education-society subjects, which constitute the key foundation for the development of PEB theory. The cluster is related to the influencing mechanism of cognition, emotion and other related driving factors on individual environmental protection behavior. Among the mechanisms, emotions are normally defined as dichotomic classification of positive and negative, which predicts an individual's PEB (Kals et al., 1999; Verhoef, 2005; Mkono \& Hughes, 2020). For instance, some researchers advocated cognitive dissonance theory believe that, people may show a highly positive attitude towards PEB but a low level of PEB, due to negative emotions that lead to their cognitive or behavioral correction (e. g. Vining \& Ebreo, 2002; Lu et al., 2020). Moreover, the expected emotion could be a crucial psychological motivation for individuals to perform PEBs (Carrus et al., 2008; Amatulli et al., 2019). The generation of emotion is closely associated with past experience or past behavior. Likewise, Collado et al. (2013) proved that children's natural experience could enhance their affinity of emotion towards nature and thus improve their future PEB. In addition, information characteristics such as information sources (e.g., Witzling et al., 2015), information content (e.g., Pelletier \& Sharp, 2008), compatibility of information framework and information content (e.g., Lee \& Oh, 2014), and information dissemination (e.g., Li et al., 2018) could all possibly affect the extent to which the recipient supports environmental protection behaviors.

\section{C2 Environmental Values, Attitudes and Environmental} Knowledge Similarly, articles in C2 are also related to psychosocial - educational - social subjects. The cluster mainly focuses on internal and external factors that influence PEBs. The internal factors involve environmental attitudes, values, environmental concerns, etc. First, the majority of scholars selected pro-environmental attitudes and values as the pivot of research. Some scholars believed that attitude can well predict PEBs (Carmi et al., 2015; Arnon et al., 2015); whereas some 
other researchers revealed inconsistencies between attitudes and behaviors, and had reservations about environmental attitudes (e.g., Weigel, 1983). Furthermore, the predictive effect of pro-environmental values on PEB has not been completely validated (Dietz et al., 2005). Second, as for environmental concern, there is a lack of widely accepted definition. Some scholars regarded environmental concern as an individual's assessment or attitude towards the extent to which his or her own or others' behaviors had affected the environment (Fransson \& Garling, 1999), and argued that environmental concern could be used interchangeably with environmental attitude (Parsa \& Deng, 2008). On the other hand, external variables (e. g. socioeconomic and demographic factors) should also be involved in the decision-making process of individual PEBs. Environmental attitudes could vary according to local norms, gender, income, age, living environment and other factors, which will eventually result in behavioral differences (Varah et al., 2020). Likewise, the theoretical system for differences of factors such as gender, age, and education in regard to environmental values and environmental concerns, is being perfected in process.

\section{C3 Pro-Environmental Intentions, Ethical Characteristics and} Practices C3 is related to the theoretical development stage of multi-disciplinary knowledge integration. Based on the knowledge of psychology, articles in this cluster investigated whether PEB intentions are predictive indicators of PEB. They address the research question by elaborating PEB with the theory or the extended theory of planned behavior. Generally, the articles in this cluster focuse on the relations among individual's environmental responsibility, personal norms, religious beliefs and their PEBs PEB intentions (Kaiser \& Shimoda, 1999; Martin \& Bateman, 2014; Zhang et al., 2018a). Furthermore, some articles in this cluster explored whether there are bound effects (e.g., Tiefenbeck et al., 2013) or positive spillover effects (e.g., Penz et al., 2019) among various kinds of PEBs. For example, moral licensing theory has been used to explain bound effect of PEBs. It is arguable that psychological permission could be initially provided for engaging in moral behaviors such as PEB, but the moral behaviors shall be reduced at a later point in time (Meijers et al., 2019).

\section{C6 Energy Conservation Behaviors' Interventions and} Changes The articles in C6 mainly focuses on the incentives and interventions, such as green reward, punishment, fairness, product ecological design etc., which could promote individuals' energy conservation behaviors. Some scholars argued that, the implementation of external intervention measures such as reward and punishment could be effective in facilitating individuals' energy conservation behaviors in the short term. However, achieving satisfactory PEBs in the long run requires incentives and intervention measures focusing on individuals' internal motivation (Webb et al., 2013; Legault et al., 2020). As one of such incentives, environmental identity has been found to play a significant role in determining individuals' initiative implementation of energy conservation behaviors (Whitmarsh \& O Neill, 2010; Van der Werff et al., 2013). For instance, Van der Werff et al. (2013) conducted a research on the intended use of green energy. Their results shown that environmental self-identity enhanced individuals' internal motivation i.e. the sense of obligation in an environmental protection way. This subsequently affected their decisions of green energy use. Similarly, the product design with interventions aiming at energy conservation mainly relied on the ecological properties, feedback and guidance (Kuo et al., 2018). The application of new technology and the adjustment of electrical device of product attributes should be the effective means of intervention via design. Additionally, intergenerational justice and hedonism could also serve as promoting/ retarding factors that affect individuals' energy conservation behaviors.

\section{Organizational Level of PEB}

C4 Organization Sustainable Development Strategy and Social Responsibility Implementation C4 is the theoretical development phase of theory integration and involves in-depth investigation on various disciplinary knowledge. Articles in this cluster mainly focus on organizational sustainability and investigate the interactions among organizational management practice, leadership and employee green behaviors.

Specifically, these studies reveal that leaders with different leadership styles or leaders' environmental attitudes exert various influence on employees' green behaviors. For instance, environmentally specific servant leadership, responsible leadership and leader green behavior have a directly positive impact (Luu, 2020; Ying et al., 2020; Zhao \& Zhou, 2019; Kim et al., 2017) or indirectly positive effects (Luu, 2019b; Han et al., 2019; Zhao \& Zhou, 2019; Kim et al., 2017) on the employee OCBE. Perceived organizational support (Afsar et al., 2016; Luu, $2019 b$ ) could serves as moderator on this relationship, while green organizational climate (Priyankara et al., 2018; Khan et al., 2019) and employees' motivation to implement PEBs (Graves et al., 2013; Han et al., 2019) serve as mediator between leadership and employee OCBE.

Additionally, some studies have shown that organizational green HRM practices have a positive impact on employees' green behavior (e.g., Bin Saeed et al., 2019), and there is a positive relationship between $\mathrm{OCBE}$ at team and individual levels (e.g., Luu, 2019a).

Moreover, articles in this cluster also inspect the realization path of organizational social responsibility. The realization of organizational social responsibility requires close collaborations between organizations and stakeholders. Findings of those articles suggest that environmental sustainability of an 
organization is largely affected by individuals' environmental behavior (Bin Saeed et al., 2019). The social responsibility perceived by employees affects employees' green behaviors (e.g., De Roeck \& Farooq, 2018) and employees' organizational citizenship behaviors for the environment (e.g., Tian \& Robertson, 2019) through the mediating effect of organizational identification. Furthermore, employees' green behaviors facilitate organizational green performance (Luu, 2019a).

\section{Social Level of PEB}

C5 Sustainable Tourism Management C5 is the theoretical development phase of mutual integration and focuses on ecotourism and hotel accommodation. The sustainable development of tourism destinations is closely related to the environmental protection actions of stakeholders. Specifically, tourists are the key actors affecting the sustainable development of tourism destinations and hotel industry (Wang et al., 2020). Studies in this cluster have reported that the determinants of tourists' environment-responsible behavior include travel experience (e.g., Lee \& Jan, 2015), place attachment (e.g., Chow et al., 2019), recreation experience (e.g., Lin \& Lee, 2020), etc. Meanwhile, other stakeholders, such as management organizations and residents of tourism destinations, also play significant roles in the realization process for the sustainable tourism (e.g., Lee \& Jan, 2019). Compared with tourists, residents of the tourism destination have a larger impact on the ecological environment of the tourism destination ( $\mathrm{Su}$ et al., 2018). The hotel industry and hotel employees are also stakeholders (Rezapouraghdam et al., 2018; Okumus et al., 2019; Pham et al., 2019) that researchers pay attention to. Research on tourism destination management agencies, on the other hand, mostly examine issues related to destination environmental quality (Liu et al., 2019a), destination reputation (e. g., Su et al., 2019), etc.

\section{C7 Environmental Policies, Norms and Sustainable} Consumption This group of research is in the theory application phase of PEBs and mainly focuses on environmental governance policy and norms research.

To date, the vast majority of countries all over the world have made lots of efforts to cope with environmental issues, including establishing national environmental laws and regulations, facilitating and joining global ecological and environmental governance institutions, holding international environmental conferences and concluding international environmental protection conventions. Nevertheless, actors such as individuals, localities or nations all face similar social dilemmas in the face of environmental issues, especially the global ones. For instance, some individuals or countries are to bear costs related to implementation of pro-environment actions, which could benefit the whole world (Carattini et al., 2015). In light of such social dilemmas, some scholars believe that it is necessary to establish social norms to constrain individual behaviors (e.g., Thogersen, 2008), while other scholars point out that if mutual trust is built between individuals or countries, it could facilitate more collective environmental protection behaviors. In other words, trust and policies are complementary (Joshi et al., 2000; Ostrom, 2009; Carattini et al., 2015).

Moreover, some other studies have explored whether different kinds of norms, such as subjective/descriptive/injunctive norms, affect specific PEBs in different ways (Zhang et al., 2018b; Choi et al., 2015;Leoniak \& Cwalina, 2019; Oceja \& Berenguer, 2009). In addition, some scholars focused on how to effectively carry out green marketing activities and further cultivate residents' sustainable consumption behaviors. These studies identify various important factors that affect residents' sustainable consumption behaviors include eco-label (Testa et al., 2015; Chekima et al., 2016), consumers' personality characteristics (Gordon-Wilson \& Modi, 2015; Trivedi et al., 2015), etc.

\section{Conclusion, Limitation and Further Research}

\section{Conclusions}

The current research used bibliometrics as the analytical method to systematically review the literatures on PEB research during the period of 1979-2020. Citation analysis, co-word analysis and cluster analysis were conducted to the 1038 literatures and high-frequency keywords. We draw the following conclusions based on our findings:

(1) The study of PEB has gone through three periods, including the budding period (1979-1990), the exploratory period (1991-2013), and the rapid growth period (20142020). The international journals that have published most relevant articles on PEB include Environment and Behavior, Journal of Environmental Psychology, and Sustainability.

(2) The Citation analysis of the literatures shows that the research of PEB mainly fall into the following discipline clusters: Psychology-Education-Society, EconomicsEconomic-Politics, Environmental-ToxicologyNutrition, Plant-Ecology-Zoology, Earth-GeologyGeophysics, Molecular-Biology-Genetics, and Systems-Computing-Computer. Specifically, various subject fields provided theoretical support for the research on PEB. As shown by the number of documents in the different research fields, PEB research is closely related to Environmental sciences \& Ecology (544), Environmental studies (397), Psychology (343), Psychology Multidisciplinary and other disciplines (239). The research fields of Environmental sciences \& 
Ecology, Environmental studies, Education \& Education research, Psychology, Business, etc. are among the first to see PEB related studies. Later, PEB studies also emerge in research fields such as Political science, Government \& Law, Sociology, Management, Hospitality (Leisure), etc. Finally, some researchers in the other fields, such Energy \& Fuels, Geography, Engineering, Development studies, Ethics, etc., also began to pay attention to PEB. Nevertheless, papers from those fields are relatively few.

(3) The co-occurrence analysis on high-frequency keywords indicates that the hot keywords on PEB are mainly related to Attitudes, Values, PEB intentions, Sustainable consumption, etc. Some other, by observing the frequency of co-occurrence between high-frequency keywords, the mainstream research content is determined.

(4) The cluster analysis of PEB high-frequency keywords reveals that these keywords fall into seven clusters. For further analysis, we divide these clusters into three stages in the horizontal direction and three levels in the vertical direction. Specially, as shown in Fig. 7, horizontally, our analysis identified individual levels such as 'Environmental cognition, emotion and motivation process $(\mathrm{C} 1)$ ', 'Environmental values, attitudes and environmental knowledge $(\mathrm{C} 2)$ ', 'Pro-environmental intentions, ethical characteristics and practices(C3)' and 'Energy conservation behaviors' interventions and changes(C6)'. We also revealed organizational levels related to 'Organization sustainable development strategy and social responsibility implementation (C4)', as well as social levels such as 'Sustainable tourism management(C5)' and 'Environmental policies, norms and Sustainable consumption(C7)'. Vertically, theoretical basis level includes $\mathrm{C} 1$ and $\mathrm{C} 2$. Theory development level includes $\mathrm{C} 3, \mathrm{C} 4$ and $\mathrm{C} 5$; and theory application level includes $\mathrm{C} 6$ and $\mathrm{C} 7$.

\section{Limitations}

This article still has several limitations. First, although we have selected the 11 most representative search terms to construct the search formula, the list may not be comprehensive. And due to the lag of journal publication, the number of annual publications we retrieved may not be real, but all of these have little impact on the conclusions of entire evolutionary process study. Second, although Web of science is the core database widely used in visualization research (SCI and SSCI) (Liao et al., 2018), the amount of social sciences and humanities literature included in the database is probably less than that of Google Scholar. (Harzing \& Alakangas, 2016). We select Web of science because the search interface of Google Scholar cannot export the text format recognized by bibliometric analysis software (Martín-Martín et al., 2020). Future research might obtain standardized data from Google scholar with the help of technologies such as Excel VBA to further verify our findings. Third, while co-occurrence analysis of keywords is often used to explore the evolution trend of specific research topics (Chen et al., 2016; Liu et al., 2018; Chen et al., 2019), the results of such analysis may be limited by the representative deviation of keywords in some articles. Therefore, future researchers may need to manually verify the representativeness of the original keywords in the data set during the data processing.

\section{Future Research}

(1) We suggest that future research topics should be based on specific social backgrounds and closely follow social hot issues. Recently, due to the Covid-19 pandemic, the massive use of medical materials produces a large amount of waste and domestic garbage, which poses a serious threat to the ecological balance. In order to prevent the spread of the disease and environmental pollution, first, governments of all countries need to establish top-down norms and systems in accordance with the actual conditions of the country. Seeking the best treatment plan with the lowest impact on the environment under the help of technical means and establishing systematic thinking in each link of classification, collection, transportation, storage, and processing. Second, the joint efforts from the people around the world are needed. Therefore, it is important for future researchers to answer questions such as "How to ensure that enterprises working on the disposal of medical waste consciously fulfill their environmental social responsibilities and strictly fulfill the relevant national pollution discharge standards?" And "in the post-pandemic era, will individual residents reflect on their own PEBs due to the pandemic, thereby affecting their own PEBs?"

(2) The environment that we live in a complex symbiotic system. Currently, most studies investigated merely a single behavioral agent. Very few researches incorporate multiple stakeholders within a same symbiotic system together into a single research framework. Different stakeholders may exhibit different value pursuit and interests. This could affect the collaboration and trust between different stakeholders, which could ultimately influence the realization of the overall environmental protection target. Moreover, the internal formation and influence mechanisms of different PEBs may vary. Therefore, it is necessary to build a system framework integrating value pursuit of multiple stakeholders for PEBs. For example, Lu et al. (2019) discussed the influence of the pro-environment value fit of employees and organizations on the relationship among employees' 
PEBs. He et al. (2018) constructed a dynamic evolutionary game model with the three liability subjects, such as government, tourism enterprises and tourists, in order to identify the incentive mechanism for promoting the green development of tourism. As such, previous studies have mainly focused on how organizations, employees (individuals), governments affect PEBs. Little attention has been paid to the influence of communities, thirdparty institutions and other stakeholders.

(3) To date, researchers mainly use various statistical methods to study PEB, including Meta-analysis, Structural equation modelling, Multilevel regression analysis, Factor analysis, Path analysis, etc. we maintain that, in order to achieve the optimization of research results and to further identify unknown influence variables, a diversified research method system needs to be constructed. For example, researchers may utilize Fuzzy-Set Qualitative Comparative Analysis (fsQCA) to study PEB. This method is able to analyze a wide range of small and medium-sized cases by assigning and calculating condition and outcome variables. The analysis identifies sufficient or necessary conditions and key combination of conditions that affect a particular outcomes (Pappas et al., 2019). Furthermore, fsQCA can identify potential asymmetric causal relationships or explanatory relationships (Berg-Schlosser \& De Meur, 2009). This method is suitable for exploring unexplored constructs and causal relationships in the field of PEB. Another potential technique for PEB study is the electroencephalogram technology, which uses electroencephalography and other equipment to receive the brain waves of the subject, and identify, decompose and analyze the frequency of the brain waves to obtain the required data (Casson et al., 2018). It is suitable for the research of PEB, which involves mostly more subjective perception variables. Therefore, future research can use EEG equipment to improve the accuracy of the measurement results of perception variables. In summary, optimizing experimental design and results requires a combination of a variety of interdisciplinary research methods or thinking, which is an inevitable trend for future research in the PEB field.

(4) Existing research on PEB spillover effects focuses on across PEBs spillover and cross-contextual spillover between different scenarios. Spillover effects refer to the impact of interventions on a certain behavior on subsequent non-targeted behaviors. When initial measures are taken to increase the possibility of other subsequent behaviors, positive spillover effects might appear (Truelove et al., 2014; Carrico et al., 2018). By definition, the spillover effect implies the sequential logic between the initial behavior and the subsequent behavior. In the experimental design of most studies, the description of the measured behavior interval is relatively vague. The PEB 2 is often measured immediately after the intervention for the PEB 1 is implemented. However, in real life, the time intervals between PEBs are usually not fixed. Therefore, we believe that it is necessary to answer the following questions: When will behavior overflow occur? How will the time interval between the initial PEB and the subsequent PEB affect the spillover effect?

Nevertheless, the answers to those questions remain unclear in literature. Therefore, future research needs to explore whether the time interval is an important variable that adjust the spillover process in the future. Furthermore, to date, research on PEB spillovers mainly focuses on the settings of home and workplace, especially the spillover from the workplace to the family (Rashid \& Mohammad, 2011; Andersson et al., 2012). There are few studies on PEB spillovers in other non-work fields apart from family (Nilsson et al., 2017). At the same time, individuals occupying a position or status in a particular social structure will have expectations about how to exercise power or meet others' expectations about how they will assume obligations. Therefore, in the future, researchers may need to investigate PEBs in various context based on individual role identities. Specifically, they may explore the mechanism of PEB spillover between homes, workplaces, and specific public areas (such as dormitory life, entertainment venues), and identify key elements that can enhance crosscontextual PEBs.

(5) PEB falls into the category of ethical behavior (Krettenauer, 2017). In recent years, scholars have explored the primary reasons for the differences in PEBs from the perspective of ethical dilemmas, mainly focusing on the choice of a single agent's dual interest preferences (Czap et al., 2015; Chuang et al., 2016; Lei et al., 2020), and how this choice affects his or her PEB. However, individuals are faced with the ethical dilemmas of "self-interest" and "altruism" when they implement PEBs (Davis, 2018). Among them, "self-interest" is related to the ethical norms that oneself agrees with or needs; "altruism" is related to the different ethical norms that multiple stakeholders agree or expect, which involves various ethical conflicts. Conflicts in the field of PEB may be a manifestation of conflicts between individuals' own various interests or the interests of multiple stakeholders. The diverse individual self-interests, as well as the various interests among multiple stakeholders form the stratification of interests framework. In future research, multiple causal chains within the stratification of interests and ethical dilemmas could be incorporated into one single research framework to systematically study the internal mechanisms 
that form the ethical dilemma of PEBs. This could provide a better understanding of how individuals or organizations practice PEBs consciously.

Acknowledgements This research was financially supported by Chinese National Natural Science Foundation Grant (71974189); the Youth Project of Chinese National Natural Science Foundation Grant (71603255); the Key Project of Chinese National Social Science Foundation Grant (18AZD014); the Major Project of Chinese National Social Science Foundation Grant (16ZDA056); Think Tank of Green Safety Management and Policy Science (2018WHCC03).

Author's Contribution Hui Lu: Funding acquisition, Project administration, Data curation, Validation, Writing - original draft, Writing - review \& editing. Wei bo Zhang: Data curation, Formal analysis, Investigation, Software, Writing - original draft. Beidi Diao: Investigation, Writing original draft. Yan Liu: Investigation, Writing - original draft. Hong Chen: Conceptualization, Methodology, Funding acquisition, Resources, Supervision, Validation, Writing - review \& editing. Ruyin Long: Writing - review \& editing. Shaohan Cai: Writing - review \& editing.

Data Availability The datasets generated during and/or analyzed during the current study are available from the corresponding author on reasonable request.

\section{Declarations}

Ethical Approval Not applicable.

Informed Consent Informed consent was obtained from all individual participants included in the study.

Conflict of Interest The authors declare that they have no conflict of interest.

\section{References}

Aboelela, S. W., Larson, E., Bakken, S., Carrasquillo, O., Formicola, A., Glied, S. A., Haas, J., \& Gebbie, K. M. (2007). Defining interdisciplinary research: Conclusions from a critical review of the literature. Health Services Research, 42(1p1), 329-346. https://doi.org/10. 1111/j.1475-6773.2006.00621.x.

Afsar, B., Badir, Y., \& Kiani, U. S. (2016). Linking spiritual leadership and employee pro-environmental behavior: The influence of workplace spirituality, intrinsic motivation, and environmental passion. Journal of Environmental Psychology, 45, 79-88. https://doi.org/ 10.1016/j.jenvp.2015.11.011.

Alp, E., Ertepinar, H., Tekkaya, C., \& Yilmaz, A. (2008). A survey on Turkish elementary school students' environmental friendly behaviours and associated variables. Environmental Education Research, 14(2), 129-143. https://doi.org/10.1080/13504620802051747.

Amatulli, C., De Angelis, M., Peluso, A. M., Soscia, I., \& Guido, G. (2019). The effect of negative message framing on green consumption: An investigation of the role of shame. Journal of Business Ethics, 157, 1111-1132. https://doi.org/10.1007/s10551-017-3644$\mathrm{x}$.

Andersson, M., Eriksson, O., \& Borgstede, C. V. (2012). The effects of environmental management systems on source separation in the work and home settings. Sustainability, 4(6), 1292-1308. https:// doi.org/10.3390/su4061292.

Arnon, S., Orion, N., \& Carmi, N. (2015). Environmental literacy components and their promotion by institutions of higher education: An Israeli case study. Environmental Education Research, 21(7), 1029 1055. https://doi.org/10.1080/13504622.2014.966656.

Batagelj, V., \& Mrvar, A. (1998). Pajek- program for large network analysis. Connections, 21, 47-57.

Berg-Schlosser, D., \& De Meur, G. (2009). Comparative research design: Case and variable selection. In B. Rihoux \& C. C. Ragin (Eds.), Configurational comparative methods: Qualitative comparative analysis (QCA) and related techniques (pp. 19-32). Thousand Oaks, CA: Sage Publications, Inc..

Bin Saeed, B., Afsar, B., Hafeez, S., Khan, I., Tahir, M., \& Afridi, M. A. (2019). Promoting employee's proenvironmental behavior through green human resource management practices. Corporate Social Responsibility and Environmental Management, 26(2), 424-438. https://doi.org/10.1002/csr.1694.

Boiral, O., \& Paillé, P. (2012). Organizational citizenship behaviour for the environment: Measurement and validation. Journal of Business Ethics, 109, 431-445. https://doi.org/10.1007/s10551-011-1138-9.

Borden, R. J., \& Schettino, A. P. (1979). Determinants of environmentally responsible behavior. The Journal of Environmental Education, 10(4), 35-39. https://doi.org/10.1080/00958964.1979. 9941906.

Bratt, C., Stern, P. C., Matthies, E., \& Nenseth, V. (2015). Home, car use, and vacation: The structure of environmentally significant individual behavior. Environment and Behavior, 47(4), 436-473. https:// doi.org/10.1177/0013916514525038.

Buunk, B. (1981). Knowledge, utility and sense of efficacy as determinants of environmentally responsible behavior. Psychological Reports, 48(1), 9-10. https://doi.org/10.2466/pr0.1981.48.1.9.

Callon, M., Courtial, J., Turner, W. A., \& Bauin, S. (1983). From translations to problematic networks: An introduction to co-word analysis. Social Science Information, 22(2), 191-235. https://doi.org/10. 1177/053901883022002002003.

Carattini, S., Baranzini, A., \& Roca, J. (2015). Unconventional determinants of greenhouse gas emissions: The role of trust. Special Issue: Ecological Economics and Institutional Dynamics, 25(4), 243-257. https://doi.org/10.1002/eet.1685.

Carmi, N., Arnon, S., \& Orion, N. (2015). Seeing the forest as well as the trees: General vs. specific predictors of environmental behavior. Environmental Education Research, 21(7), 1011-1028. https://doi. org $/ 10.1080 / 13504622.2014 .949626$.

Carrico, A. R., Raimi, K. T., Truelove, H. B., \& Eby, B. (2018). Putting your money where your mouth is: An experimental test of proenvironmental spillover from reducing meat consumption to monetary donations. Environment and Behavior, 50(7), 723-748. https:// doi.org/10.1177/0013916517713067.

Carrus, G., Passafaro, P., \& Bonnes, M. (2008). Emotions, habits and rational choices in ecological behaviours: The case of recycling and use of public transportation. Journal of Environmental Psychology, 28(1), 51-62. https://doi.org/10.1016/j.jenvp.2007.09. 003.

Casaló, L. V., Escario, J. J., \& Rodriguez-Sanchez, C. (2019). Analyzing differences between different types of pro-environmental behaviors: Do attitude intensity and type of knowledge matter? Resources, Conservation and Recycling, 149, 56-64. https://doi.org/10.1016/j. resconrec.2019.05.024.

Casson, A. J., Abdulaal, M., Dulabh, M., Kohli, S., Krachunov, S., \& Trimble, E. (2018). Electroencephalogram. In T. Tamura \& W. Chen (Eds.), Seamless healthcare monitoring (pp. 45-81). Cham, Switzerland: Springer. https://doi.org/10.1007/978-3-319-69362-0 2 .

Chan, K. (1998). Mass communication and pro-environmental behaviour: Waste recycling in Hong Kong. Journal of Environmental 
Management, 52(4), 317-325. https://doi.org/10.1006/jema.1998. 0189.

Chekima, B., Wafa, S. A. W. S. K., Igau, O. A., Chekima, S., \& Sondoh, S. L. (2016). Examining green consumerism motivational drivers: Does premium price and demographics matter to green purchasing? Journal of Cleaner Production, 112(4), 3436-3450. https://doi.org/ 10.1016/j.jclepro.2015.09.102.

Chen, C. (2004). Searching for intellectual turning points: Progressive knowledge domain visualization. Proceedings of the National Academy of Sciences of the United States of America, 101(suppl 1), 5303-5310. https://doi.org/10.1073/pnas.0307513100.

Chen, C. (2006). CiteSpace II: Detecting and visualizing emerging trends and transient patterns in scientific literature. Journal of the American Society for Information Science and Technology, 57(3), 359-377. https://doi.org/10.1002/asi.20317.

Chen, C., \& Leydesdorff, L. (2014). Patterns of connections and movements in dual-map overlays: A new method of publication portfolio analysis. The Journal of the Association for Information Science and Technology, 65(2), 334-351. https://doi.org/10.1002/asi.22968.

Chen, X. W., Chen, J. M., Wu, D. S., Xie, Y. J., \& Li, J. (2016). Mapping the research trends by co-word analysis based on keywords from funded project. Procedia Computer Science, 91, 547-555. https:// doi.org/10.1016/j.procs.2016.07.140.

Chen, H., Feng, Y., Li, S. S., Zhang, Y. Y., \& Yang, X. X. (2019). Bibliometric analysis of theme evolution and future research trends of the type a personality. Personality and Individual Differences, 150, 109507. https://doi.org/10.1016/J.PAID.2019.109507.

Cheung, L. T. O., Ma, A. T. H., Lee, K. M. Y., Lee, J. C. K., \& Lo, Y. L. (2019). How does political orientation influence one's environmental attitude and behaviour? Debate over country park conservation in Hong Kong. Environmental Science \& Policy, 99, 115-122. https:// doi.org/10.1016/j.envsci.2019.05.026.

Choi, H., Jang, J., \& Kandampully, J. (2015). Application of the extended VBN theory to understand consumers' decisions about green hotels. International Journal of Hospitality Management, 51, 87-95. https://doi.org/10.1016/j.ijhm.2015.08.004.

Chow, A. S. Y., Ma, A. T. H., Wong, G. K. L., Lam, T. W. L., \& Cheung, L. T. O. (2019). The impacts of place attachment on environmentally responsible behavioral intention and satisfaction of Chinese nature-based tourists. Sustainability-Basel, 11(20), 558520. https:// doi.org/10.3390/su11205585.

Chuang, Y. T., Xie, X. F., \& Liu, C. (2016). Interdependent orientations increase pro-environmental preferences when facing self-interest conflicts: The mediating role of self-control. Journal of Environmental Psychology, 46, 96-105. https://doi.org/10.1016/j. jenvp.2016.04.001.

Collado, S., Staats, H., \& Corraliza, J. A. (2013). Experiencing nature in children's summer camps: Affective, cognitive and behavioural consequences. Journal of Environmental Psychology, 33, 37-44. https://doi.org/10.1016/j.jenvp.2012.08.002.

Cornelissen, G., Dewitte, S., Warlop, L., \& Yzerbyt, V. (2007). Whatever people say I am, that's what I am: Social labeling as a social marketing tool. International Journal of Research in Marketing, 24(4), 278-288. https://doi.org/10.1016/j.ijresmar.2007.05.001.

Czap, N. V., Czap, H. J., Lynne, G. D., \& Burbach, M. E. (2015). Walk in my shoes: Nudging for empathy conservation. Ecological Economics, 118, 147-158. https://doi.org/10.1016/j.ecolecon. 2015.07.010.

Daily, B. F., Bishop, J. W., \& Govindarajulu, N. (2009). A conceptual model for organizational citizenship behavior directed toward the environment. Business \& Society, 48, 243-256. https://doi.org/10. $1177 / 0007650308315439$.

De Bellis, N. (2009). Bibliometrics and citation analysis: From the science citation index to cybermetrics. Lanham, MD: Scarecrow Press.

De Roeck, K., \& Farooq, O. (2018). Corporate social responsibility and ethical leadership: Investigating their interactive effect on employees' socially responsible behaviors. Journal of Business Ethics, 151, 923-939. https://doi.org/10.1007/s10551-017-3656-6.

Dietz, T., Fitzgerald, A., \& Shwom, R. (2005). Environmental values. Annual Review of Environment and Resource, 30, 335-372. https:// doi.org/10.1146/annurev.energy.30.050504.144444.

Ding, Y., Chowdhury, G. G., \& Foo, S. (2001). Bibliometric cartography of information retrieval research by using co-word analysis. Information Processing \& Management, 37(6), 817-842. https:// doi.org/10.1016/S0306-4573(00)00051-0.

Dolnicar, S., \& Leisch, F. (2008). Selective marketing for environmentally sustainable tourism. Tourism Management, 29(4), 672-680. https://doi.org/10.1016/j.tourman.2007.07.010.

Dolnicar, S., Crouch, G. I., \& Long, P. (2008). Environment-friendly tourists: What do we really know about them? Journal of Sustainable Tourism, 16(2), 197-210. https://doi.org/10.2167/ jost738.0.

Ellen, P. S., Wiener, J. L., \& Cobbwalgren, C. (1991). The role of perceived consumer effectiveness in motivating environmentally conscious behaviors. Journal of Public Policy \& Marketing, 10(2), 102-117. https://doi.org/10.1177/074391569101000206.

Fairchild, R. J. (2008). The manufacturing sector's environmental motives: A game-theoretic analysis. Journal of Business Ethics, 79, 333-344. https://doi.org/10.1007/s10551-007-9401-9.

Fitchett, J. A., \& Prothero, A. (1999). Contradictions and opportunities for a green commodity. Advances in Consumer Research, 26(1), $272-275$.

Forstmann, M., \& Sagioglou, C. (2017). Lifetime experience with (classic) psychedelics predicts pro-environmental behavior through an increase in nature relatedness. Journal of Psychopharmacology, 31(8), 975-988. https://doi.org/10.1177/0269881117714049.

Fraj-Andres, E., Martinez-Salinas, E., \& Matute-Vallejo, J. (2009). Factors affecting corporate environmental strategy in spanish industrial firms. Business Strategy and the Environment, 18(8), 500-514. https://doi.org/10.1002/bse.611.

Fransson, N., \& Garling, T. (1999). Environmental concern: Conceptual definitions, measurement methods, and research findings. Journal of Environmental Psychology, 19(4), 369-382. https://doi.org/10. 1006/jevp.1999.0141.

Garfield, E. (1979). Citation indexing: Its theory and application in science, technology, and humanities. New York: Wiley.

Geiger, N., Swim, J. K., \& Glenna, L. (2019). Spread the green word: A social community perspective into environmentally sustainable behavior. Environment and Behavior, 51(5), 561-589. https://doi.org/ $10.1177 / 0013916518812925$.

Gordon-Wilson, S., \& Modi, P. (2015). Personality and older consumers' green behaviour in the UK. Futures, 71, 1-10. https://doi.org/10. 1016/j.futures.2015.05.002.

Graves, L. M., Sarkis, J., \& Zhu, Q. (2013). How transformational leadership and employee motivation combine to predict employee proenvironmental behaviors in China. Journal of Environmental Psychology, 35, 81-91. https://doi.org/10.1016/j.jenvp.2013.05. 002.

Han, Z. Y., Wang, Q., \& Yan, X. (2019). How responsible leadership predicts organizational citizenship behavior for the environment in China. Leadership \& Organization Development Journal, 40(3), 305-318. https://doi.org/10.1108/LODJ-07-2018-0256.

Harland, P., Staats, H., \& Wilke, H. (1999). Explaining proenvironmental intention and behavior by personal norms and the theory of planned behavior. Journal of Applied Social Psychology, 29(12), 25052528. https://doi.org/10.1111/j.1559-1816.1999.tb00123.x.

Harzing, A. W., \& Alakangas, S. (2016). Google scholar, scopus and the web of science: A longitudinal and cross-disciplinary comparison. Scientometrics, 106, 787-804. https://doi.org/10.1007/s11192-0151798-9. 
He, P., He, Y., \& Xu, F. F. (2018). Evolutionary analysis of sustainable tourism. Annals of Tourism Research, 69, 76-89. https://doi.org/10. 1016/j.annals.2018.02.002

Hennessey, B. A., \& Amabile, T. M. (2010). Creativity. Annual Review of Psychology, 61, 569-598. https://doi.org/10.1146/annurev.psych. 093008.100416.

Hornsey, M. J., \& Fielding, K. S. (2020). Understanding (and reducing) inaction on climate change. Social Issues and Policy Review, 14(1), 3-35. https://doi.org/10.1111/sipr.12058.

Hou, Q., Mao, G. Z., Zhao, L., Du, H. B., \& Zuo, J. (2015). Mapping the scientific research on life cycle assessment: A bibliometric analysis. The International Journal of Life Cycle Assessment, 20, 541-555. https://doi.org/10.1007/s11367-015-0846-2.

Hou, J., Yang, X., \& Chen, C. (2018). Emerging trends and new developments in information science: a document co-citation analysis (2009-2016). Scientometrics, 115, 869-892. https://doi.org/10. 1007/s11192-018-2695-9.

Jiang, D. X., Tang, C., \& Zhang, A. D. (2004). Cluster analysis for gene expression data: A survey. IEEE Transactions on Knowledge and Data Engineering, 16(11), 1370-1386. https://doi.org/10.1109/ TKDE.2004.68.

Joshi, N. N., Ostrom, E., Shivakoti, G. P., \& Lam, W. F. (2000). Institutional opportunities and constraints in the performance of farmer-managed irrigation systems in Nepal. Asia-Pacific Journal of Rural Development, 10(2), 67-92. https://doi.org/10.1177/ 1018529120000205.

Juvan, E., \& Dolnicar, S. (2014). Can tourists easily choose a low carbon footprint vacation? Journal of Sustainable Tourism, 22(2), 175-194. https://doi.org/10.1080/09669582.2013.826230.

Kaiser, F. G. (1998). A general measure of ecological behavior. Journal of Applied Social Psychology, 28(5), 395-422. https://doi.org/10. 1111/j.1559-1816.1998.tb01712.x.

Kaiser, F. G., \& Shimoda, T. A. (1999). Responsibility as a predictor of ecological behaviour. Journal of Environmental Psychology, 19(3), 243-253. https://doi.org/10.1006/jevp.1998.9123.

Kaiser, F. G., Hubner, G., \& Bogner, F. X. (2005). Contrasting the theory of planned behavior with the value-belief-norm model in explaining conservation behavior. Journal of Applied Social Psychology, 35(10), 2150-2170. https://doi.org/10.1111/j.1559-1816.2005. tb02213.x.

Kals, E., Schumacher, D., \& Montada, L. (1999). Emotional affinity toward nature as a motivational basis to protect nature. Environment and Behavior, 31(2), 178-202. https://doi.org/10. 1177/00139169921972056.

Kapecki, T. (2020). Elements of sustainable development in the context of the environmental and financial crisis and the COVID-19 pandemic. Sustainability, 12(15), 6188. https://doi.org/10.3390/ su12156188.

Kerr, J. M., Lapinski, M. K., Liu, R. W., \& Zhao, J. H. (2017). Long-term effects of payments for environmental services: Combining insights from communication and economics. Sustainability, 9(9), 1627. https://doi.org/10.3390/su9091627.

Khan, M. A. S., Jianguo, D., Ali, M., Saleem, S., \& Usman, M. (2019). Interrelations between ethical leadership, green psychological climate, and organizational environmental citizenship behavior: A moderated mediation model. Frontiers in Psychology, 10, 1977. https://doi.org/10.3389/fpsyg.2019.01977.

Kim, A., Kim, Y., Han, K., Jackson, S. E., \& Ployhart, R. E. (2017). Multilevel influences on voluntary workplace green behavior: Individual differences, leader behavior, and coworker advocacy. Journal of Management, 43(5), 1335-1358. https://doi.org/10. $1177 / 0149206314547386$.

Kim, A., Kim, Y., \& Han, K. (2019). A cross level investigation on the linkage between job satisfaction and voluntary workplace green behavior. Journal of Business Ethics, 159, 1199-1214. https://doi.org/ 10.1007/s10551-018-3776-7.
Krettenauer, T. (2017). Pro-environmental behavior and adolescent moral development. Journal of Research on Adolescence, 27(3), 581-593. https://doi.org/10.1111/jora.12300.

Kuo, T. C., Tseng, M. L., Lin, C. H., Wang, R. W., \& Lee, C. H. (2018). Identifying sustainable behavior of energy consumers as a driver of design solutions: The missing link in eco-design. Journal of Cleaner Production, 192, 486-495. https://doi.org/10.1016/j.jclepro.2018. 04.250 .

Kurz, T., Linden, M., \& Sheehy, N. (2007). Attitudinal and community influences on participation in new curbside recycling initiatives in Northern Ireland. Environment and Behavior, 39(3), 367-391. https://doi.org/10.1177/0013916506294152.

Lee, T. H., \& Jan, F. H. (2015). The effects of recreation experience, environmental attitude, and biospheric value on the environmentally responsible behavior of nature-based tourists. Environmental Management, 56(1), 193-208. https://doi.org/10.1007/s00267-0150488-y.

Lee, T. H., \& Jan, F. H. (2019). Can community-based tourism contribute to sustainable development? Evidence from residents' perceptions of the sustainability. Tourism Management, 70, 368-380. https://doi. org/10.1016/j.tourman.2018.09.003.

Lee, S. A., \& Oh, H. (2014). Effective communication strategies for hotel guests' green behavior. Cornell Hospitality Quarterly, 55(1), 52-63. https://doi.org/10.1177/1938965513504029.

Lee, T. H., Jan, F. H., \& Yang, C. C. (2013). Conceptualizing and measuring environmentally responsible behaviors from the perspective of community-based tourists. Tourism Management, 36, 454-468. https://doi.org/10.1016/j.tourman.2012.09.012.

Legault, L., Bird, S., Powers, S. E., Sherman, A., Schay, A., Hou, D., \& Janoyan, K. (2020). Impact of a motivational intervention and interactive feedback on electricity and water consumption: A smart housing field experiment. Environment and Behavior, 52(6), 666-692. https://doi.org/10.1177/0013916518811433.

Lei, H. D., Khan, I., \& Li, S. P. (2020). The inhabitants' dual interest preferences and their impact on pro-environmental behavior in China. Environmental Science and Pollution Research, 27(11), 12308-12319. https://doi.org/10.1007/s11356-020-07760-1.

Leoniak, K. J., \& Cwalina, W. (2019). The role of normative prompts and norm support cues in promoting light-switching behavior: A field study. Journal of Environmental Psychology, 64, 1-11. https://doi. org/10.1016/j.jenvp.2019.04.014.

Leydesdorff, L., Rafols, I., \& Chen, C. (2013). Interactive overlays of journals and the measurement of interdisciplinarity on the basis of aggregated journal-journal citations. Journal of the American Society for Information Science and Technology, 64(12), 25732586. https://doi.org/10.1002/asi.22946.

Li, F., Li, M., Guan, P., Ma, S., \& Cui, L. (2015). Mapping publication trends and identifying hot spots of research on internet health information seeking behavior: A quantitative and co-word biclustering analysis. Journal of Medical Internet Research, 17(3), e81. https:// doi.org/10.2196/jmir.3326.

Li, W., Tian, L., \& Batool, H. (2018). Impact of negative information diffusion on green behavior adoption. Resources, Conservation and Recycling, 136, 337-344. https://doi.org/10.1016/j.resconrec.2018. 04.026 .

Liao, H., Tang, M., Luo, L., Li, C., Chiclana, F., \& Zeng, X. J. (2018). A bibliometric analysis and visualization of medical big data research. Sustainability, 10(1), 166. https://doi.org/10.3390/SU10010166.

Lin, Y. H., \& Lee, T. H. (2020). How do recreation experiences affect visitors' environmentally responsible behavior? Evidence from recreationists visiting ancient trails in Taiwan. Journal of Sustainable Tourism, 28(5), 705-726. https://doi.org/10.1080/09669582.2019. 1701679.

Liobikienè, G., Grincevičienè, Š., \& Bernatonienė, J. (2017). Environmentally friendly behaviour and green purchase in Austria 
and Lithuania. Journal of Cleaner Production, 142(4), 3789-3797. https://doi.org/10.1016/j.jclepro.2016.10.084.

Liu, B., Chen, H., \& Huang, X. (2018). Map changes and theme evolution in work hours: A co-word analysis. International Journal of Environmental Research and Public Health, 15(5), 1039. https:// doi.org/10.3390/ijerph15051039

Liu, J., Wu, J. S., \& Che, T. (2019a). Understanding perceived environment quality in affecting tourists' environmentally responsible behaviours: A broken windows theory perspective. Tourism Management Perspectives, 31, 236-244. https://doi.org/10.1016/j. tmp.2019.05.007.

Liu, X. M., Zhou, J. Y., Xue, Y. T., \& Qian, S. Y. (2019b). Analysis of property management ecological behavior in China based on the grounded theory: The influencing factors and the behavior model. Journal of Cleaner Production, 235, 44-56. https://doi.org/10.1016/ j.jclepro.2019.06.300.

Lu, H., Liu, X., Chen, H., \& Long, R. Y. (2019). Employee-organization pro-environmental values fit and pro-environmental behavior: The role of supervisors' personal values. Science and Engineering Ethics, 25(2), 519-557. https://doi.org/10.1007/s11948-017-0007$\mathrm{z}$.

Lu, H., Zou, J. X., Chen, H., \& Long, R. Y. (2020). Promotion or inhibition? Moral norms, anticipated emotion and employee's proenvironmental behavior. Journal of Cleaner Production, 258, 120858. https://doi.org/10.1016/j.jclepro.2020.120858.

Luu, T. T. (2019a). Green human resource practices and organizational citizenship behavior for the environment: The roles of collective green crafting and environmentally specific servant leadership. Journal of Sustainable Tourism, 27(8), 1167-1196. https://doi.org/ 10.1080/09669582.2019.1601731.

Luu, T. T. (2019b). Building employees' organizational citizenship behavior for the environment: The role of environmentally-specific servant leadership and a moderated mediation mechanism. International Journal of Contemporary Hospitality Management, 31(1), 406-426. https://doi.org/10.1108/IJCHM-07-2017-0425.

Luu, T. T. (2020). Integrating green strategy and green human resource practices to trigger individual and organizational green performance: The role of environmentally-specific servant leadership. Journal of Sustainable Tourism, 28(8), 1193-1222. https://doi.org/10.1080/ 09669582.2020 .1729165$.

Martin, W. C., \& Bateman, C. R. (2014). Consumer religious commitment's influence on ecocentric attitudes and behavior. Journal of Business Research, 67(2), 5-11. https://doi.org/10.1016/j.jbusres. 2013.03.006

Martín-Martín, A., Thelwall, M., Orduna-Malea, E., \& López-Cózar, E. D. (2020). Google scholar, microsoft academic, scopus, dimensions, web of science, and OpenCitations' COCI: A multidisciplinary comparison of coverage via citations. Scientometrics, 126(1), 871906. https://doi.org/10.1007/s11192-020-03690-4.

Mccoy, K., Oliver, J. J., Borden, D. S., \& Cohn, S. I. (2018). Nudging waste diversion at Western State Colorado University: Application of behavioral insights. International Journal of Sustainability in Higher Education, 19(3), 608-621. https://doi.org/10.1108/IJSHE05-2017-0063.

Meijers, M. H. C., Noordewier, M. K., Verlegh, P. W. J., Zebregs, S., \& Smit, E. G. (2019). Taking close others' environmental behavior into account when striking the moral balance? Evidence for vicarious licensing, not for vicarious cleansing. Environment and Behavior, 51(9-10), 1027-1054. https://doi.org/10.1177/ 0013916518773148 .

Mkono, M., \& Hughes, K. (2020). Eco-guilt and eco-shame in tourism consumption contexts: Understanding the triggers and responses. Journal of Sustainable Tourism, 28(8), 1223-1244. https://doi.org/ 10.1080/09669582.2020.1730388.
Moon, S., Jeong, S. Y., \& Choi, Y. (2017). Moderating effects of trust on environmentally significant behavior in Korea. Sustainability-Basel, 9(3), 4153. https://doi.org/10.3390/su9030415.

Moore, W. C., Meyers, D. A., Wenzel, S. E., Teague, W. G., Li, H., Li, X., D’Agostino R Jr, Castro, M., Curran-Everett, D., Fitzpatrick, A. M., Gaston, B., Jarjour, N. N., Sorkness, R., Calhoun, W. J., Chung, K. F., Comhair, S. A., Dweik, R. A., Israel, E., Peters, S. P., Busse, W. W., Erzurum, S. C., Bleecker, E. R., \& National Heart, Lung, and Blood Institute's Severe Asthma Research Program. (2010). Identification of asthma phenotypes using cluster analysis in the severe asthma research program. American Journal of Respiratory and Critical Care Medicine, 181(4), 315-323. https://doi.org/10. 1164/rccm.200906-0896OC.

Nilsson, A., Bergquist, M., \& Schultz, W. P. (2017). Spillover effects in environmental behaviors, across time and context: A review and research agenda. Environmental Education Research, 23(4), 573589. https://doi.org/10.1080/13504622.2016.1250148.

Oceja, L., \& Berenguer, J. (2009). Putting text in context: The conflict between pro-ecological messages and anti-ecological descriptive norms. The Spanish Journal of Psychology, 12(2), 657-666. https://doi.org/10.1017/S113874160000202X.

Okumus, F., Köseoglu, M. A., Chan, E., Hon, A., \& Avci, U. (2019). How do hotel employee's environmental attitudes and intentions to implement green practices relate to their ecological behavior? Journal of Hospitality and Tourism Management, 39, 193-200. https://doi.org/10.1016/j.jhtm.2019.04.008.

Oskamp, S., \& Schultz, P. (2005). Attitudes and opinions (3th ed.). New York: Psychology Press.

Ostrom, E. (2009). A polycentric approach for coping with climate change. World Bank Policy Research Working Paper, 5095. https://doi.org/10.1596/1813-9450-5095.

Otto, S., \& Pensini, P. (2017). Nature-based environmental education of children: Environmental knowledge and connectedness to nature, together, are related to ecological behaviour. Global Environmental Change, 47, 88-94. https://doi.org/10.1016/j. gloenvcha.2017.09.009.

Otto, S., Kibbe, A., Henn, L., Hentschke, L., \& Kaiser, F. G. (2018). The economy of e-waste collection at the individual level: A practice oriented approach of categorizing determinants of e-waste collection into behavioral costs and motivation. Journal of Cleaner Production, 204, 33-40. https://doi.org/10.1016/j.jclepro.2018.08. 293.

Paillé, P., Boiral, O., \& Chen, Y. (2013). Linking environmental management practices and organizational citizenship behaviour for the environment: A social exchange perspective. The International Journal of Human Resource Management, 24(18), 3552-3575. https://doi.org/10.1080/09585192.2013.777934.

Pappas, I. O., Giannakos, M. N., \& Sampson, D. G. (2019). Fuzzy set analysis as a means to understand users of 21 st-century learning systems: The case of mobile learning and reflections on learning analytics research. Computers in Human Behavior, 92, 646-659. https://doi.org/10.1016/j.chb.2017.10.010.

Parsa, S., \& Deng, L. X. (2008). Capital markets' reactions to social information announcements. International Journal of Accounting and Finance, 1(1), 107-120. https://doi.org/10.1504/IJAF.2008. 020239.

Pelletier, L. G., \& Sharp, E. (2008). Persuasive communication and proenvironmental behaviours: How message tailoring and message framing can improve the integration of behaviours through selfdetermined motivation. Canadian Psychology, 49(3), 210-217. https://doi.org/10.1037/a0012755.

Penz, E., Hartl, B., \& Hofmann, E. (2019). Explaining consumer choice of low carbon footprint goods using the behavioral spillover effect in german-speaking countries. Journal of Cleaner Production, 214, 429-439. https://doi.org/10.1016/j.jclepro.2018.12.270. 
Pham N. T., Tučková, Z., \& Jabbour, C. J. C. (2019). Greening the hospitality industry: How do green human resource management practices influence organizational citizenship behavior in hotels? A mixed-methods study. Tourism Management, 72, 386-399. https:// doi.org/10.1016/j.tourman.2018.12.008.

Pickett, G. M., Kangun, N., \& Grove, S. J. (1993). Is there a general conserving consumer? A public policy concern. Journal of Public Policy \& Marketing, 12(2), 234-243. https://doi.org/10.1177/ 074391569101200208.

Priyankara, H. P. R., Luo, F., Saeed, A., Nubuor, S. A., \& Jayasuriya, M. P. F. (2018). How does leader's support for environment promote organizational citizenship behaviour for environment? A multitheory perspective. Sustainability-Basel, 10(1), 2711. https://doi. org/10.3390/su10010271.

Rashid, N. A. R., \& Mohammad, N. (2011). Spillover of environmentally friendly behaviour phenomenon: The mediating effect of employee organizational identification. OIDA International Journal of Sustainable Development, 2(12), 29-42 Available at SSRN: https://ssrn.com/abstract=1983566.

Rezapouraghdam, H., Alipour, H., \& Darvishmotevali, M. (2018). Employee workplace spirituality and pro-environmental behavior in the hotel industry. Journal of Sustainable Tourism, 26(5), 740 758. https://doi.org/10.1080/09669582.2017.1409229.

Rezvani, Z., Jansson, J., \& Bengtsson, M. (2018). Consumer motivations for sustainable consumption: The interaction of gain, normative and hedonic motivations on electric vehicle adoption. Business Strategy and the Environment, 27(8), 1272-1283. https://doi.org/10.1002/ bse. 2074

Rifkin, J. (2015). The zero marginal cost society: The internet of things, the collaborative commons, and the eclipse of capitalism. New York: Palgrave Macmillan.

Rojšek, I. (2001). From red to green: Towards the environmental management in the country in transition. Journal of Business Ethics, 33(1), 37-50. https://doi.org/10.1023/A:1011977116496.

Ronda-pupo, G. A., \& Guerras-martin, L. Á. (2012). Dynamics of the evolution of the strategy concept 1962-2008: A co-word analysis. Strategic Management Journal, 33(2), 162-188. https://doi.org/10. 1002/smj.948.

Spano, G., D’Este, M., Giannico, V., Carrus, G., Elia, M., Lafortezza, R., Panno, A., \& Sanesi, G. (2020a). Are community gardening and horticultural interventions beneficial for psychosocial well-being? A meta-analysis. International Journal of Environmental Research and Public Health, 17(10), 3584. https://doi.org/10.3390/ ijerph17103584.

Spano, G., Giannico, V., Elia, M., Bosco, A., Lafortezza, R., \& Sanesi, G. (2020b). Human health-environment interaction science: An emerging research paradigm. Science of the Total Environment, 704, 135358. https://doi.org/10.1016/j.scitotenv.2019.135358.

Stern, P. C. (2011). Contributions of psychology to limiting climate change. American Psychologist, 66(4), 303-314. https://doi.org/ 10.1037/a0023235.

Su, L., \& Swanson, S. R. (2017). The effect of destination social responsibility on tourist environmentally responsible behavior: Compared analysis of first-time and repeat tourists. Tourism Management, 60, 308-321. https://doi.org/10.1016/j.tourman.2016.12.011.

Su, L., Huang, S. S., \& Pearce, J. (2018). How does destination social responsibility contribute to environmentally responsible behaviour? A destination resident perspective. Journal of Business Research, 86, 179-189. https://doi.org/10.1016/j.jbusres.2018.02.011.

Su, L., Huang, S. S., \& Pearce, J. (2019). Toward a model of destination resident-environment relationship: The case of Gulangyu, China. Journal of Travel \& Tourism Marketing, 36(4), 469-483. https:// doi.org/10.1080/10548408.2019.1568954.

Testa, F., Iraldo, F., Vaccari, A., \& Ferrari, E. (2015). Why eco-labels can be effective marketing tools: Evidence from a study on Italian consumers. Business Strategy and the Environment, 24(4), 252265. https://doi.org/10.1002/bse.1821.

Thøgersen, J. (2008). Social norms and cooperation in real-life social dilemmas. Journal of Economic Psychology, 29(4), 458-472. https://doi.org/10.1016/j.joep.2007.12.004.

Tian, Q., \& Robertson, J. L. (2019). How and when does perceived CSR affect employees' engagement in voluntary pro-environmental behavior? Journal of Business Ethics, 155(4), 399-412. https://doi. org/10.1007/s10551-017-3497-3.

Tiefenbeck, V., Staake, T., Roth, K., \& Sachs, O. (2013). For better or for worse? Empirical evidence of moral licensing in a behavioral energy conservation campaign. Energy Policy, 57, 160-171. https://doi.org/ 10.1016/j.enpol.2013.01.021.

Toni, M., Renzi, M. F., \& Mattia, G. (2018). Understanding the link between collaborative economy and sustainable behaviour: An empirical investigation. Journal of Cleaner Production, 172, 44674477. https://doi.org/10.1016/j.jclepro.2017.11.110.

Trivedi, R. H., Patel, J. D., \& Savalia, J. R. (2015). Pro-environmental behaviour, locus of control and willingness to pay for environmental friendly products. Marketing Intelligence \& Planning, 33(1), 67-89. https://doi.org/10.1108/MIP-03-2012-0028.

Truelove, H. B., Carrico, A. R., Weber, E.U., Raimi, K. T., \& Vandenbergh, M. P. (2014). Positive and negative spillover of pro-environmental behavior: An integrative review and theoretical framework. Global Environmental Change, 29, 127-138. https:// doi.org/10.1016/j.gloenvcha.2014.09.004.

Van der Werff, E., Steg, L., \& Keizer, K. (2013). It is a moral issue: The relationship between environmental self-identity, obligation-based intrinsic motivation and pro-environmental behaviour. Global Environmental Change, 23(5), 1258-1265. https://doi.org/10. 1016/j.gloenvcha.2013.07.018.

Varah, F., Mahongnao, M., Francis, D. J., \& Shimrah, T. (2020). Measuring environmental attitudes and behaviors: A study of undergraduate students in Delhi. Natural Hazards, 103, 1291-1306. https://doi.org/10.1007/s11069-020-04035-3.

Verhoef, P. C. (2005). Explaining purchases of organic meat by Dutch consumers. European Review of Agricultural Economics, 32(2), 245-267. https://doi.org/10.1093/eurrag/jbi008.

Vining, J., \& Ebreo, A. (2002). Emerging theoretical and methodological perspectives on conservation behavior. In R. B. Bechtel \& A. Churchman (Eds.), Handbook of environmental psychology (pp. 551-558). New York: Wiley.

Vlek, C. (2000). Essential psychology for environmental policy making. International Journal of Psychology, 35(2), 153-167. https://doi. org $/ 10.1080 / 002075900399457$.

Wang, X., Zhou, K., \& Liu, W. (2018). Value congruence: A study of green transformational leadership and employee green behavior. Frontiers in Psychology, 9, 1946. https://doi.org/10.3389/fpsyg. 2018.01946.

Wang, S., Wang, J., Li, J., \& Zhou, K. (2020). How and when does religiosity contribute to tourists' intention to behave proenvironmentally in hotels? Journal of Sustainable Tourism, 28(8), 1120-1137. https://doi.org/10.1080/09669582.2020.1724122.

Webb, D., Soutar, G. N., Mazzarol, T., \& Saldaris, P. (2013). Selfdetermination theory and consumer behavioural change: Evidence from a household energy-saving behaviour study. Journal of Environmental Psychology, 35, 59-66. https://doi.org/10.1016/j. jenvp.2013.04.003.

Weigel, R.H. (1983). Environmental attitudes and the prediction of behavior. In N. R. Feimer \& E. S. Geller (Eds.), Environmental Psychology: Directions and perspectives (pp. 257-287). New York: Praeger.

Whitmarsh, L., \& O’Neill, S. (2010). Green identity, green living? The role of proenvironmental self-identity in determining consistency across diverse proenvironmental behaviours. Journal of 
Environmental Psychology, 30(3), 305-314. https://doi.org/10. 1016/j.jenvp.2010.01.003.

Witzling, L., Shaw, B., \& Amato, M. S. (2015). Incorporating information exposure into a theory of planned behavior model to enrich understanding of proenvironmental behavior. Science Communication, 37(5), 551-574. https://doi.org/10.1177/ 1075547015593085.

Xie, H., Zhang, Y. W., \& Duan, K. F. (2020). Evolutionary overview of urban expansion based on bibliometric analysis in web of science from 1990 to 2019. Habitat International, 95, 102100. https://doi. org/10.1016/j.habitatint.2019.102100.

Yang, Y., Wu, M. Z., \& Cui, L. (2012). Integration of three visualization methods based on co-word analysis. Scientometrics, 90(2), 659673. https://doi.org/10.1007/s11192-011-0541-4.

Ying, M., Faraz, N. A., Ahmed, F., \& Raza, A. (2020). How does servant leadership foster employees' voluntary green behavior? A sequential mediation model. International Journal of Environmental Research and Public Health, 17(5), 17925. https://doi.org/10. 3390/ijerph17051792.

Young, W., \& Middlemiss, L. (2012). A rethink of how policy and social science approach changing individuals' actions on greenhouse gas emissions. Energy Policy, 41, 742-747. https://doi.org/10.1016/j. enpol.2011.11.040.

Zhang, Q., Yang, J., Sun, Z., \& Wu, F. (2017a). Analyzing the impact factors of energy-related $\mathrm{CO} 2$ emissions in China: What can spatial panel regressions tell us? Journal of Cleaner Production, 161, 1085-1093. https://doi.org/10.1016/j.jclepro.2017.05.071.

Zhang, Y., Huang, K., Yu, Y., \& Yang, B. B. (2017b). Mapping of water footprint research: A bibliometric analysis during 2006-2015. Journal of Cleaner Production, 149, 70-79. https://doi.org/10. 1016/j.jclepro.2017.02.067.
Zhang, X., Liu, J., \& Zhao, K. (2018a). Antecedents of citizens' environmental complaint intention in China: An empirical study based on norm activation model. Resources, Conservation and Recycling, 134, 121-128. https://doi.org/10.1016/j.resconrec.2018.03.003.

Zhang, Y., Moyle, B. D., \& Jin, X. (2018b). Fostering visitors' proenvironmental behaviour in an urban park. Asia Pacific Journal of Tourism Research, 23(7), 691-702. https://doi.org/10.1080/ 10941665.2018.1487457.

Zhang, H., Zhang, Y., Song, Z., \& Lew, A. A. (2019). Assessment bias of environmental quality (AEQ), consideration of future consequences (CFC), and environmentally responsible behavior (ERB) in tourism. Journal of Sustainable Tourism, 27(5), 609-628. https://doi.org/10. 1080/09669582.2019.1597102.

Zhao, R., \& Chen, B. (2014). Applying author co-citation analysis to user interaction analysis: A case study on instant messaging groups. Scientometrics, 101(2), 985-997. https://doi.org/10.1007/s11192014-1314-7.

Zhao, H., \& Zhou, Q. (2019). Exploring the impact of responsible leadership on organizational citizenship behavior for the environment: A leadership identity perspective. Sustainability-Basel, 11(4), 944. https://doi.org/10.3390/su11040944.

Zong, Q. J., Shen, H. Z., Yuan, Q. J., Hu, X. W., Hou, Z. P., \& Deng, S. G. (2013). Doctoral dissertations of library and information science in China: A co-word analysis. Scientometrics, 94(2), 781-799. https:// doi.org/10.1007/s11192-012-0799-1.

Publisher's Note Springer Nature remains neutral with regard to jurisdictional claims in published maps and institutional affiliations. 